\title{
Oncogenic Signaling Pathways in Cancer: An Overview
}

\author{
Afshin Derakhshani ${ }^{1 \#}$, Zeinab Rostami ${ }^{2}$, Sina Taefehshokr ${ }^{3}$, Hossein Safarpour ${ }^{4}$, Reza Vaezi \\ Astamal 5, Nima Taefehshokr 6, Nazila Alizadeh ${ }^{7}$, Antonella Argentiero ${ }^{8}$, Nicola Silvestris ${ }^{9 *}$, \\ Behzad Baradaran 10*
}

\author{
${ }^{1}$ Immunology Research Center, Tabriz University of Medical Sciences, Tabriz, \\ Iran; email: afshin.derakhshani94@gmail.com \\ ${ }^{2}$ Cellular \& Molecular Research Center, Birjand University of Medical Sciences Birjand, Iran; \\ email: zeinabrostamy73@gmail.com \\ ${ }^{3}$ Immunology Research Center, Tabriz University of Medical Sciences, Tabriz, Iran; \\ email: sinataefehshokr@gmail.com \\ ${ }^{4}$ Cellular \& Molecular Research Center, Birjand University of Medical Sciences Birjand, Iran; \\ email: safarpour701@yahoo.com \\ ${ }^{5}$ Immunology Research Center, Tabriz University of Medical Sciences, Tabriz, Iran; \\ email: rezavaezi72@gmail.com \\ ${ }^{6}$ Division of Biosciences, Department of Life Sciences, Brunel University London, Kingston Lane, UB8 3PH, \\ UK; email: n.taefehshokr@gmail.com \\ ${ }^{7}$ Immunology Research Center, Tabriz University of Medical Sciences, Tabriz, Iran; \\ email: alizadeh_imm@yahoo.com \\ ${ }^{8}$ Medical Oncology Unit, IRCCS Istituto Tumori “Giovanni Paolo II”, Bari, 70124, Italy; email: \\ argentieroantonella@gmail.com \\ ${ }^{9}$ Medical Oncology Unit, IRCCS Istituto Tumori “Giovanni Paolo II”, Bari, 70124, Italy; Department of \\ Biomedical Sciences and Human Oncology, University of Bari “Aldo Moro", Bari, 70124, Italy; \\ n.silvestris@oncologico.bari.it \\ ${ }^{10}$ Immunology Research Center, Tabriz University of Medical Sciences, Tabriz, Iran; \\ email: baradaranb@tbzmed.ac.ir
}

\#The authors contributed equally to this work.

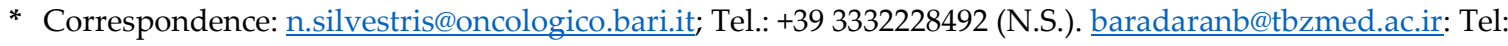
+98 4133371440 (B.B.)

\begin{abstract}
Cancer is a leading cause of death worldwide. It is theorized that underlying genetic and epigenetic changes enable cells to proliferate out of control by escaping regulatory mechanisms. The progression of cancer is associated with increased cell proliferation, metabolic modifications, resistance to apoptosis, genetic instability, induction of angiogenesis and augmented migratory capability. Recent developments in DNA and RNA analysis have made it possible to study these genetic changes systematically. These advances have enabled us to possess a deeper knowledge of the signaling pathways and involved processes. In-depth studies of the pathways involved in carcinogenesis have led to the identification of pathways that may be targeted for therapeutic purposes. In this review, we provide an overview of the relevant mechanisms and pathways involved in the development and progression of cancer.
\end{abstract}

Keywords: cancer, cell signaling, therapeutic targets, signaling pathways 


\section{Introduction}

Cancer is the $2^{\text {nd }}$ leading cause of death worldwide. It has been theorized that genetic and/or epigenetic modifications are the potential drivers of malignancy $[1,2]$ The process of carcinogenesis is the result of increasing cell proliferation, resistance to apoptosis, genetic instability, induction of angiogenesis, metabolic modifications, and augmented migratory capability [3,4]. The trigger for most of these changes is the dysregulation of cellular signal transduction pathways [5]. Recent progress in DNA sequencing has made it possible to study these genetic changes systematically providing us with a deeper knowledge of the various signaling pathways and involved processes $[6,7]$. Several experiments have described various signaling components over the past decades that have helped build a molecular structure for the many types of signal transduction pathways [8]. As abovementioned, genetic or epigenetic alterations in tumor cells are the root cause of cancer. Furthermore, the tumor cells develop several well-defined characteristics [3] and in addition to augmented cell proliferation, these include resistance to apoptosis, metabolic changes, induction of angiogenesis, and genetic instability as well as enhanced migratory capacity. Most of these characteristics are based on the dysregulation of cellular signal transduction pathways [9]. In this review, the various pathways involved in many types of cancer are considered to identify all of cancer's tricks and also the roles of main related genes in the cancer pathways are evaluated.

\section{Tumorigenesis and signaling pathways}

An increasing number of studies have illustrated that numerous tumor suppressor- and proto-oncogenes contribute to tumorigenesis when inactivated or activated by mutations, respectively [10]. It is believed that the cells must acquire certain key properties, sometimes referred to as the signs of cancer, to shape a tumor [3,11,12]. These effective modifications include apoptosis prevention, angiogenesis, limitless potential for replication and invasion. In most cases, biological functions are preserved by one, or many, groups of genes that cooperate in functional pathways. It has been recognized that several signaling pathways contribute to carcinogenesis [13]. Genetic changes in cancer cells regulate signaling pathways that lead to tumorigenesis-related disruption of the control processes. Oncogenic mutations can affect proteins implicated in several signaling pathways, such as Hedgehog (Hh), Wnt and Hippo, which not only are frequently activated in many physiological responses but also in cancer development and invasiveness [14-17]. Wnt pathway cross talks with $\mathrm{Hh}$ and Hippo pathways, which has implications for theragnostic targets in cancers [18-20]. Several pieces of evidence indicate that association therapeutic approaches combining Wnt inhibitors and chemotherapy might enhance tumor shrinkage in several solid neoplasias, holding promise aimed at immune microenvironment targeting too [21-23]. Oncogenic mutations may affect downstream nuclear targets of signaling pathways, such as chromatin remodelers (e.g., EZH2), cell cycle effectors (e.g., cyclins), and transcription factors (e.g., NF- $\kappa B$ and Myc) [1]. Additionally, mutations and deletions may inactivate negative regulators that generally function as suppressors of tumors. P53, the so-called 'genome guardian', is one of the most frequently mutated genes in a tumor, resulting in the modulation of cell proliferation and stress signals, including DNA response and apoptosis [24,25]. An example of a mutation of another tumor suppressor that deregulates the cell cycle includes cyclin-dependent kinase inhibitors (CKIs), such as p16. Most of the tumor suppressors function as negative cytoplasmic signaling regulators, for instance, adenomatous polyposis coli protein (APC) is a negative modulator of the Wnt pathway while Phosphatase and tensin homolog (PTEN) is a negative phosphatidylinositol-4,5-bisphosphate 3-kinase (PI3K)-AKT pathway modulator [9]. It is noted that an overactive oncogene pathway could also 'undo' an irreversible cell cycle arrest, known as senescence [26-28]. This is a fail-safe mechanism for preventing proliferation triggered by abnormal oncoprotein stimulation in normal cells and is followed by modifications in cell structure, organization of chromatin, cytokine secretion, DNA 
damage, and gene expression. Oncogenesis requires changes, including loss of p53 or PTEN, which override senescence [26,27]. Another core signaling pathway relevant to tumorigenesis [29-31] includes the Receptor Tyrosine Kinase (RTK)/Ras pathway, with the highest median frequency of changes across all types of cancers. In the RTK pathway, KRAS is the most frequently modified gene, followed by B-Raf proto-oncogene (BRAF) and finally, the epidermal growth factor receptor [32]. Cancers affected by this pathway include (in descending frequency): melanoma, the gnomically-stable subtype of colorectal cancer, HER2-enriched breast cancer, pancreatic cancer, IDH1-wild-type glioma, lung adenocarcinoma and thyroid carcinoma [1]. Despite great promise in the clinical practice [33-35], overcoming target therapy resistance remains an unmet clinical need in the tailored therapy era, due to the underlying acquired mutation [36,37]. In addition, some types of tumors, such as lung cancer, EBV-positive esophagogastric cancer, squamous cell carcinoma, non-hypermutated uterine cancer, show high rates PI3K pathway changes. Another important pathway that is significantly altered in colorectal cancer is the Wnt signaling pathway. In some pathways, the alterations are distributed over many genes (e.g., cell cycle, PI3K), whereas in others, the modifications involve only limited genes (Wnt, Myc, and NRF2) [1]. Aberrations in the PI3K pathway [38] have been primarily noted to be activating events in PI3K catalytic subunit alpha (PIK3CA), less commonly in PI3K catalytic subunit beta (PIK3CB) and inactivating events in PIK3R1 or PTEN, with the most common PIK3CA and palterations occurring in breast cancer, head and neck cancer, gynecological and gastrointestinal tumors [2]. The transforming growth factor $\beta$ (TGF $\beta$ ) pathway (personal communication) has the highest rate of alteration in pancreatic and gastrointestinal cancers, whereas renal and brain cancers have almost no alterations in this pathway [3]. The Myc pathway [39] is most commonly modified in chromosome 8 amplified tumor types containing Myc, for instance, ovarian cancer and breast cancer. The role of signal transduction in cancer cell-associated processes is discussed in the next section.

\subsection{Cell proliferation}

Abnormal cell proliferation is a hallmark of most cancers and involves the modulation of multiple signaling pathways. For instance, Notch signaling can stimulate cell proliferation in T-cell acute lymphoblastic leukemia (T-ALL) via Notch1 signaling mediated hypoxia/HIF-1 $\alpha$ [40]. Furthermore, when notch signaling is triggered, subsequently a ligand binds to a Notch receptor, for example, the binding of Jagged-2 (JAG2) to Notch2 upregulates cell proliferation [41]. Notch3 is also associated with tumor cell proliferation [42] and other studies have reported that the Hairy and enhancer of split 1 (Hes1) functions as a sequence-specific transcriptional binding factor involved in cell proliferation $[43,44]$. The Hh signaling pathway through glioma-associated oncogenes (GLI2) may increase tumor proliferation, suggesting that inactivation of the Hh pathway could significantly reduce the proliferation of SMMC-7721 cell lines in hepatocellular carcinoma (HCC) [45-47]. By regulating the mechanistic target of rapamycin complex, I (mTORC1), AKT controls cell growth in the progression of the cell cycle by suppressing tuberous sclerosis complex1-2 (TSC1-TSC2) GAP activity towards Rheb, thus causing mTORC1 to be activated by GTP-bound Rheb. So, phosphorylated eukaryotic translation initiation factor 4F (eIF4)-binding protein, releasing the cap-binding factor eIF4E and permitting these to attach mRNAs, as well as ribosomal S6 kinase (RSK) and ribosomal S6 kinase (p70 RSK). This supports improved protein synthesis, which is vital for cell growth after the development of the cell cycle [48]. AKT also phosphorylates the Glycogen synthase kinase 3 (GSK3), hampering its catalytic activity, whilst the GSK3 targets and phosphorylates cyclin $\mathrm{D}$ and Myc [49,50]. Moreover, AKT impairs many inhibitors of the cell cycle, like p21 (CIP1) and cyclin-dependent kinase inhibitors (CKIs) p27 (KIP1), whereas phosphorylation contributes to 14-3-3 proteins sequestration in the cytoplasm. Phosphorylation is often controlled for decay in the situation of p27. AKT mediated phosphorylation of p21 blocks the formation of a complex proliferating nuclear cell antigen (PCNA) to suppress DNA replication, decreases its attachment to cyclin-dependent protein kinases $2 / 4$ (CDK2/CDK4) and decreases its down regulatory function to CDK2 [51]. Moreover, AKT inhibits the forkhead box (FoxO) reliant transcription of cell cycle 
inhibitors, including RBL2 (retinoblastoma-like protein 2) and p27 [52], thereby stimulating phosphorylation mouse double minute 2 homolog (MDM2) [53], the ubiquitin ligase, prompts p53 degradation, thus triggering a main cell cycle brake. AKT could also control multiple enzymes engaged in the G2/M transformation later in the cell cycle [54]. In some cases, consequent inhibition and phosphorylation of GSK3 through AKT can put an end to nuclear translocation and stabilization of the Wnt target $\beta$-catenin [55,56], a transcriptional regulator, the deterioration of which, would be introduced by GSK3 $[56,57]$. This results in the induction of $\beta$-catenin target genes that control proliferation, such as those encoding cyclin D and Myc. Moreover, AKT can immediately phosphorylate $\beta$-catenin, which causes its dissociation from cadherin cell-cell adhesion complexes, thereby improving the $\beta$-catenin pool and transcription function [58]. Several signaling pathways could promote cancer cell proliferation. For instance, cytokine and RTK signaling activate Signal Transducer and Activator of Transcription 3 (STAT3), which also activates the synthesis of Myc and cyclin D [59] and also, transcription factor NF- $\kappa B$ which activate the expression of cyclin D. Several of these signals induce cyclin E in Estrogen signaling [9], which stimulate cell proliferation through the activation of the estrogen receptors subtypes alpha (ER $\alpha)$ subtype and this also stimulates Myc and cyclin D. Disruption of the ER $\alpha$-ER $\beta$ balance or ERa mutations that produce truncated or activated proteins could dysregulate the above mechanism [60-63]. It is noted that both Ras-ERK and PI3K-AKT signaling improve signals from ERs and the androgen receptor (AR) $[64,65]$. The role of tumor suppressors is obviously critical that usually keep proliferative signals. Farthest downstream, pRB usually directly inhibits the E2F protein transcription activity until it is deactivated by CDKs through phosphorylation. P53, on the other hand, usually blocks cell proliferation by inhibiting CDK activity and by inducing CKIs in reaction to stress signals, such as DNA damage. Mutations in this tumor suppressor, thus, deregulate the proliferation of cells under hazardous circumstances that promote cancer. The CKIs themselves inhibit CDKs directly and in several cancers are also inactivated by mutation, the most prevalent example being $\mathrm{p} 16$. Upstream genes are pathway-specific tumor suppressors, such as APC and Ras-GAP NF1, which inactivate Wnt/ $\beta$-catenin signaling by enhancing GSK3 phosphorylation and thus, the destruction of $\beta$-catenin by ubiquitin. In each case, tumor suppressor mutation removes a significant brake that allows the cells to proliferate regardless of the signals that would usually restrict them. The Hippo signaling pathway plays a pivotal role in controlling proliferation contact inhibition [66] and suppressing the transcriptional Yes-associated protein (YAP) co-activator as a major tumor suppressor system in many cancers [67]. Myc, which is phosphorylated by ERK, is a significant destination of the Ras-ERK pathway, which results in its stability by suppressing ubiquitylation [50]. Myc stimulates cell proliferation by regulating various cell proliferation proteins, including those encoding CDKs, G1/S cyclins and the cell cycle-driven E2F family transcriptional factors [68], as shown in Figure 1. 


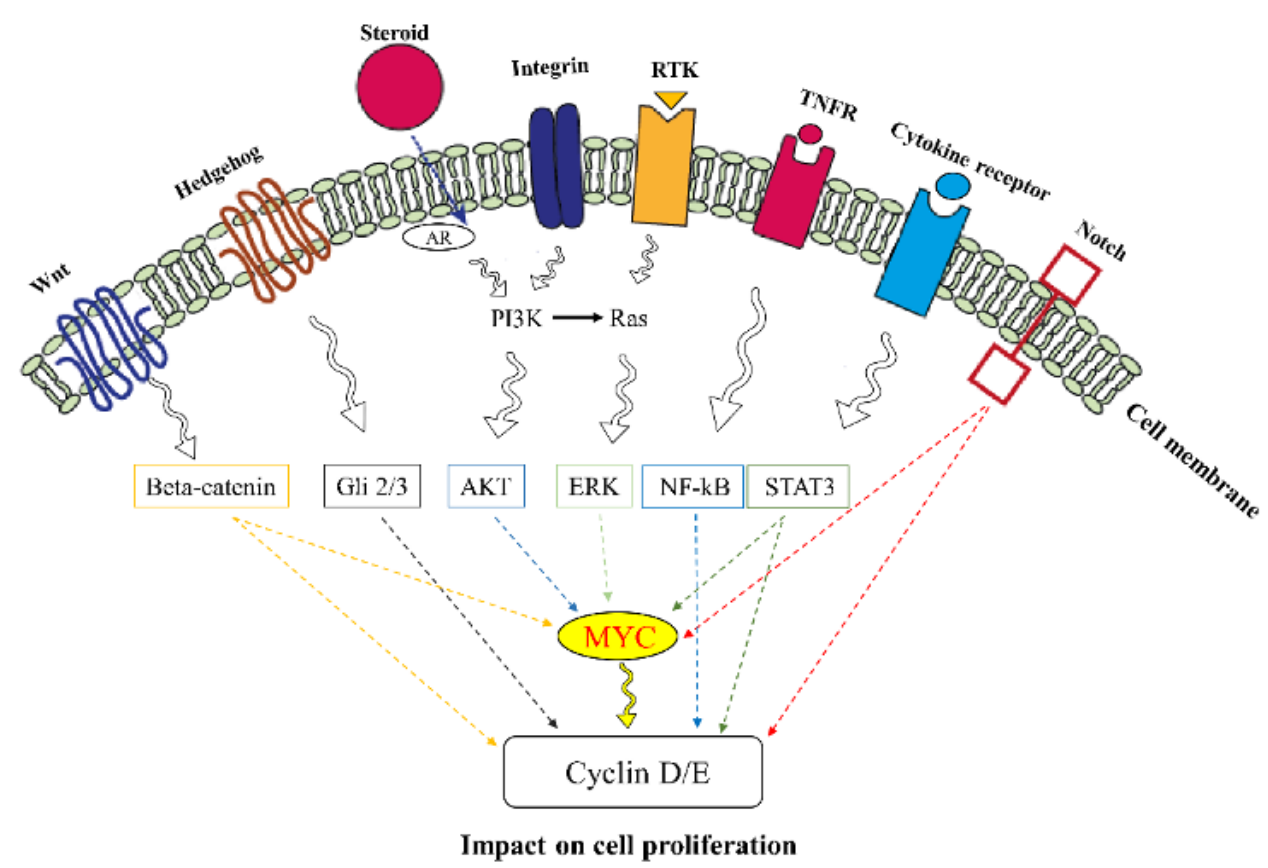

Figure 1. Signaling pathway and cell proliferation

\subsection{Cell survival}

Cell death performs as a homeostatic mechanism that usually regulates their number, but mutations can significantly disable cell death signals for cancer. For instance, Notch signaling can encourage cell survival through communication between Jagged-2 (JAG2) ligand and receptor Notch2 in cancer [69]. Moreover, studies have indicated that the Ras-ERK and PI3K-AKT pathways also control cell death in many aspects [70]. AKT itself interferes with the apoptotic signaling of mortality receptors at several stages. It phosphorylates forkhead-family transcription factors, including FoxO3A, which results in their cytoplasmic sequestration by 14-3-3 proteins. This stops the induction of proapoptotic B cell lymphoma 2 (Bcl2)-family member Bim and death ligands [e.g., Fas ligand (FasL) and TRAIL]. Also, ERK and AKT-regulated kinase RSK phosphorylate the Bcl2-family proapoptotic protein Bad, another target for 14-3-3 protein sequestration. Furthermore, AKT phosphorylates and stimulates the X-linked inhibitor-of-apoptosis protein apoptosis inhibitor (XIAP) [66]. AKT also activates NF- $\kappa \mathrm{B}$, which controls antiapoptotic enzymes (Bcl2, BCLxl, and Mcl1) and the FLIP inhibitor intracellular mortality receptor [71]. Furthermore, the ubiquitylation and degradation of p53 initiated by AKT repress apoptosis induced by p53 [53]. ERK phosphorylates Bim and the degradation targeting NF- $\kappa B$ inhibitor I $\kappa \mathrm{B} \alpha$ [72]. Additionally, RSK phosphorylates the caspase-9 scaffolding protein APAF, which inhibits the capacity of cytochrome $\mathrm{c}$ to nucleate apoptosome development and stimulates downstream apoptosis-driven caspases [73] (Figure 2). 


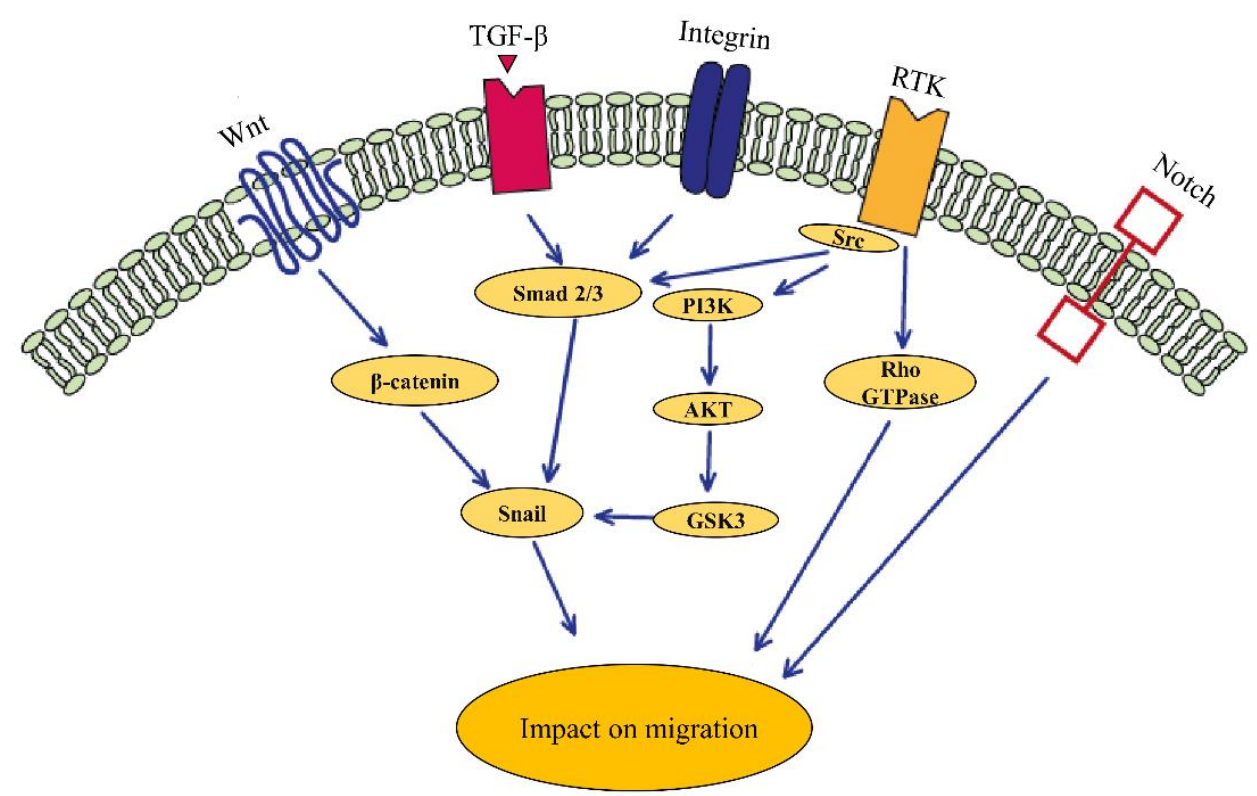

Figure 2. Signaling pathway and cell survival

\subsection{Cell metabolism}

Cancer-related mutations can contribute to increased metabolites in cancer cells [74], for instance, Isocitrate dehydrogenase 1 (IDH1) and Isocitrate dehydrogenase 2 (IDH2) mutations. This results in the production of 2-hydroxyglutarate (2HG), a metabolite that is not found in normal cells at high levels. 2HG inhibits $\alpha$-ketoglutarate-dependent enzymes, including the DNA methylation-controlled TET family and histone demethylases of the Jumonji-C domain. This causes epigenetic dysregulation that can lead to tumorigenesis. Additionally, suppression of tumor suppressors and activation of oncogenes can control parts of normal metabolic pathways effectively, producing similar metabolic changes. The PI3K-AKT pathway, for instance, uses multiple substrates to support these alterations in metabolism [51,75]. AKT regulates the transport of glucose and hexokinase, which promotes glycolysis, resulting in the production of the nucleotides and amino acids necessary for development [76]. AKT2 mediates the transport of glucose by means of several processes, which is important for the circulation of homeostasis of glucose [77]. AKT2 also regulates transcription, accumulation [78,79] and Glucose transporter 1 (GLUT1) traffic, the main glucose transporter in most cells [80]. mTORC1 signaling causes the enhanced synthesis of the hypoxia-inducible transcription factor (HIF1), which promotes lactate dehydrogenase (LDH-A) and glycolytic enzymes to upregulate glycolysis. It also triggers pyruvate dehydrogenase protein (PDK), which deactivates pyruvate dehydrogenase $(\mathrm{PDH})$ in the mitochondrion and thus, decreases glycolysis flux into the Krebs cycle [81,82]. Akt/mTORC1 enhances lipid synthesis by triggering the sterol-response-element-binding protein 1 transcription factor (SREBP), a main lipid synthesis modulator critical for tumorigenicity [83-85]. Loss of SREBP uncouples stearoyl-CoAdesaturase-1-mediated desaturation fatty acid synthase activity. Another target of AKT is ATP-citrate lyase (ACL), an enzyme vital to fatty acid, cholesterol, and isoprenoid synthesis for converting citric acid into Acetyl-CoA. mTORC1 also regulates the absorption of amino acids through promoting their translocation from intracellular vesicles to plasma membranes [86,87]. Ras-ERK signaling effects on many of metabolic impacts through Myc, which roles in glucose uptake, glycolysis and the pentose phosphate cycle [88] stimulating glutamine transporter production and glutaminase enzyme (GLS) that transforms glutamine to glutamate which can be metabolized in mitochondria $[89,90]$. Interestingly, in cancer cells is the glycolytic enzyme pyruvate kinase. Despite 
the rate of glycolysis is generally higher than in non-cancer cells, many generate an alternative type of pyruvate kinase (PKM2), which is less effective than PKM1 [91]. PKM1 continues to be functional under most physiological circumstances; however, PKM2 could be switched off by signaling through tyrosine kinases, such as Ras-ERK and PI3K-AKT RTKs [92]. Consequently, cancer cells can redirect the glycolytic intermediates flux into anabolic pathways for the production of glutathione and NADPH required to reduce oxidative stress for ribose, serine, and glycine. PKM2 could also enter the nucleus and contribute to gene expression [93][94]. Other cancer silencers not only regulate the metabolism of the cells but also, loss of p53 may lead to cancer cell glycolytic phenotype. P53 often controls glutaminase 2, a metabolic enzyme that regulates the output of glutamate transformed into mitochondrial respiratory $\alpha$-ketoglutarate and most importantly, glutathione, a critical cellular antioxidant. [95]. Loss of p53 contributes to higher oxidative damage and ROS concentrations. P53 also regulates the mevalonate pathway, which in turn, regulates the synthesis of cholesterol and produces the required intermediate protein geranylgeranylation and farnesylation [96] (Figure 3).

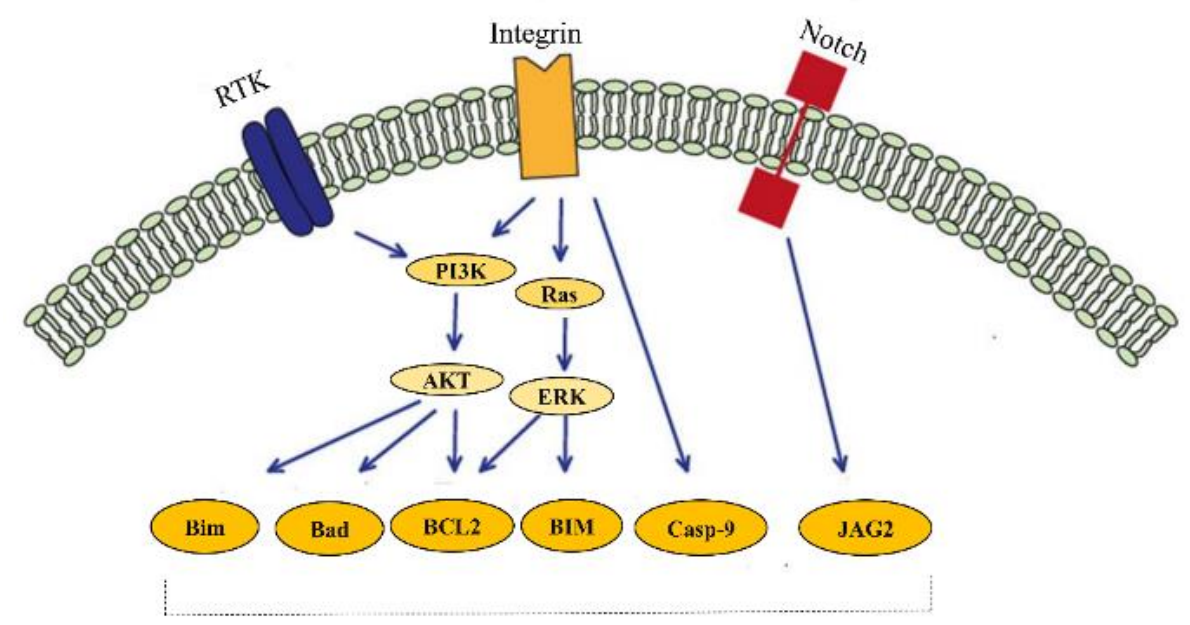

Impact on Cell survival

Figure 3. Signaling pathway and cell metabolism

\subsection{Cell migration}

Migration is regulated by adhesion receptors, chemokines, growth factors, and other stimulators [97,98], most of which are dysregulated in cancer signaling. The result of changes in these pathways is extremely contextual and isoform dependent, as with other procedures controlled by oncoprotein signaling. For instance, AKT1 explicitly represses migration by inhibiting ERK, the transcription factor NFAT, TSC2 or actin bundling induced by phosphopalladin, whilst AKT2 enhances migration by regulating integrin activity and also regulates epithelial-mesenchymal transition (EMT) [99]. It should be noted that EMT is not crucial for the dissemination of infection and tumor cells. EMT is associated with several physiological processes, such as wound regeneration, gastrulation and morphogenesis splitting [100]. This type of development is regulated by various highly organized processes, including TNF, Notch, Wnt, TGF $\beta$ and a number of growth factors [101-103]. EMT is characterized by the decrease of E-cadherin cell-cell adhesion molecules, which drives tumor progression [104,105], loss of apical-basal polarity, anchorage independence in some contexts, the 
adoption of a more fibroblast-like appearance and the acquisition of stem or progenitor-cell phenotypes as well. These would augment the capacity of the cell to invade other tissues and trigger tumors at distant sites. In certain circumstances, it is stipulated that the PI3K-AKT and Ras-ERK pathways promote EMT when hyperactivated in conjunction with other pathways involved in (e.g., Notch, Wnt, and TGF $\beta$ signaling) [106]. Several transcription factors, such as Slug, Snail, ZEB, and Twist play pivotal roles in enhancing EMT, which are modulated by AKT and ERK. For instance, AKT could phosphorylate I $\kappa B$ kinases that control NF- $\kappa \mathrm{B}$, which is a transcription factor that stimulates Snail. Also, GSK3 is phosphorylated and inactivated by AKT, which increases Snail ubiquitin-dependent degradation [107], whilst activation of AKT stimulates Snail, further enhancing EMT. Furthermore, HNRNP E1, which is a protein that stimulates translational elongation on transcripts promoting EMT is phosphorylated by AKT2 [108]. In addition to other gene expression programs that regulate phenotypic modifications connected with EMT, AP1, which is modulated by the Ras-ERK pathway, can stimulate transcription factors that enhance EMT. RAS represents a pivotal pro-tumorigenic, but to date scanty effective approaches were clinically successful [109]. This includes the stimulation of $\mathrm{E}$ cadherin, fibronectin, vimentin, integrin heterodimers [e.g., aVb6 and a5b1], cytokeratin down-regulation polarity proteins (e.g., LGL, PATJ, and Crumbs), all of which the promote cell motility. Of particular interest, by inhibiting ERK (which stimulates ZEB1), the polarity protein Scribble retains cell-cell ties [110,111]. In addition, notch signaling could promote tumor migration through Notch3 activation [43]. Ultimately, aberrant regulation of both and PI3K-AKT and Ras-ERK, thus, has the ability to play a significant function in development of cancer, as shown in Figure 4.

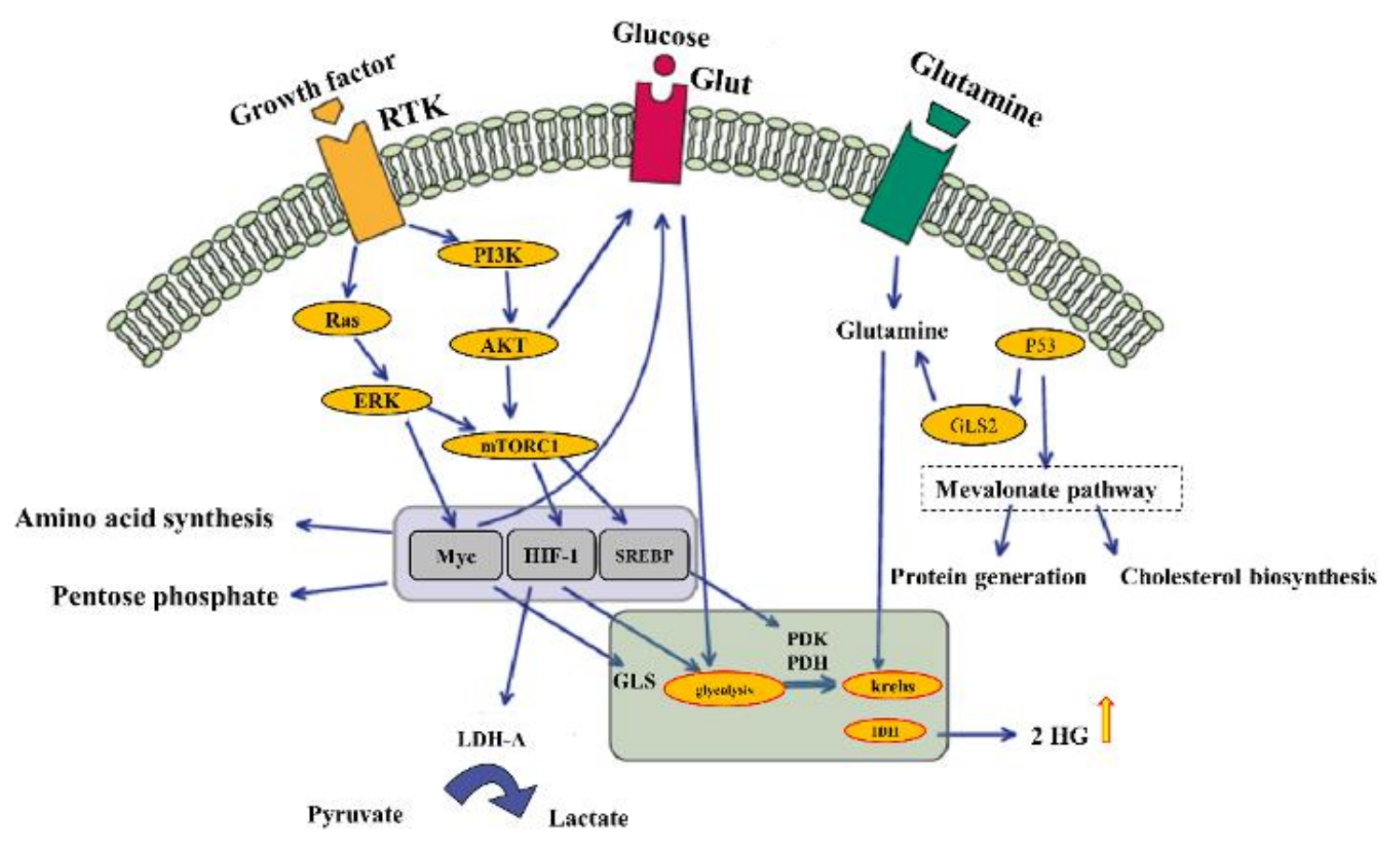

Figure 4. Signaling pathway and cell migration.

\subsection{Cell polarity}

Polarity proteins are essential for maintaining tissue architecture. Three complexes of proteins possess key functions in polarity control: the complex of Scribble, Par and Crumbs. Dysregulation of these processes is found in tumors, where aberrant expression of PI3K-AKT and Ras-ERK signaling pathways are involved. For instance, by functioning as a scaffold to link it to the protein phosphatase 
PP1G, Scribble inhibits ERK activity [111,112]. Loss of Scribble stimulates H-Ras activation, [113] whilst Ras and Myc stimulate tumor formation [114]. Moreover, loss of the Par3 polarity protein contributes to enhanced accumulation of several cell designs $[115,116]$ through various mechanisms, including JAK/STAT3 signaling PKC-dependent activation. This stimulates a metalloproteinase, MMP9 expression with the consequent death of ECM, enhanced activation of Rac and invasion, resulting in reduced cell-cell adhesion [116-118].

\subsection{Cell differentiation}

In the several cancers that disrupt the equilibrium between cell differentiation and proliferation, for example, in acute promyelocytic cancer, myeloblasts are decreased to differentiate into mature erythrocytes due to a translocation that creates a protein fusion component called PML and a receptor of retinoic acid [119]. The PML-RAR fusion protein inhibits and targets RAR genes that generally trigger differentiation, therefore blocking the RAR signal. Additional mutations then cause the over proliferation of undifferentiated myeloblasts [109]. Similarly, in colon crypts, Wnt/ $\beta$-catenin signaling [120] usually keeps enterocytes in an undifferentiated state in colon cancer, but these are blocked by $\beta$-catenin degradation caused by APC as cells migrate up to the luminous intestine surface. However, the APC tumor suppressor mutation implies that $\beta$-catenin is not demolished and can retain cells in an undifferentiated state as they die. Developmental signals may also enhance the development of cancer since they promote the proliferation of cells. For instance, mutations that trigger notch leading to acute lymphocytic leukemia [121] can promote the cell cycle and also suppress T cell apoptosis. Remarkably, notch functions in some other tissues as a tumor suppressor [122], illustrating the significance of this signaling pathway. Hh signaling pathway activation $[46,123]$ through mutations in the patched receptor occurs in medulloblastomas and basal cell carcinomas, thereby promoting cell proliferation. Hh signaling is upregulated in several malignancies through autocrine loops that influence embryonic gut tissues. As the signaling mechanisms of PI3K-AKT and Ras-ERK are triggered by fibroblast growth factor [FGF that performs a significant role in controlling cell fate], IGF and EGF and they can be regarded as behavioral signaling mechanisms. For instance, FGF4/8 signaling stimulates the Ras-ERK pathway to promote EMT and multiple cancers recapitulate this pathway throughout gastrulation [124]. Furthermore, the background is crucial. That is, whilst FGF signaling might influence angiogenesis [see below] as well as cell growth, migration, and apoptosis [see above], it may also have tumor repressive effects, retaining cells in a distinguished, non-proliferative state. The expression of FGFR2 is decreased in prostate and bladder cancer, while its expression is increased in gastric cancers [2]. In addition, notch signaling could affect cellular differentiation through Hes1 $[43,44]$ and glioma-associated oncogenes (Gli2). The Hh signaling pathway can also promote tumor differentiation $[69,125]$.

\section{Cancer and Extracellular matrix [ECM] signaling}

The ECM is a scaffold that supports tissues and provides a cell migration and adhesion substrate along with a bioactive molecules source. It is constantly being renovated away from a static framework and its conformation plays a pivotal role in controlling the behavior of the cell. Collagen, laminin, and fibronectin several other elements of the ECM act as ligands that trigger the development of the integrin. ECM signaling results in the activation of canonical processes, including PI3K-AKT and Ras-ERK signaling, in addition to other proteins, such as tyrosine kinase FAK. This is a scaffold that connects integrins with cytoskeletal proteins, adapters, and enzymes, which transmit signals from complex matrix adhesion. Also, FAK controls p53 and microRNA family members, which regulate apoptosis and the epithelial phenotype [126].

\subsection{Integrins and tumorigenesis}


Integrins are heterodimeric receptors of the cell surface that mediate ECM interactions and play a major role in the tumor microenvironment. Transmembrane structures in the cytoskeleton, specifically connect to both $\alpha$ and $\beta$ subunits in both solid [127,128] and haematological cancers [129]. Integrins are present on virtually all the surfaces of nucleated cells, thus being active in tumor cells and stromal cells and recent thorough assessments of integrin functions in tumor progression have been conducted $[130,131]$. Cancer-associated fibroblasts (CAFs) are the major producers that promote tumorigenic characteristics by initiating the remodeling of the ECM in the tumor, which triggers the survival, migration, and proliferation of the tumor cells. Also, the ECM functions as a reservoir of cytokines and growth factors that contribute to the bidirectional communication of tumor cells and stoma [132,133]. Recent studies have also illustrated the correlation between CAF and ECM in the regulation of the metastatic niche and chemoresistance [134]. Cancer associated fibroblasts broadly infiltrate tumor stroma, comprising two different cellular populations (PMID: 15549095), namely cells ancillary to ephitelium and cells with myofibroblastic differentiation, whose phenotype is characterized by alpha-SMA expression and exert a direct modulation to cancer proliferative potential, tumoral angiogenesis and disseminative potential and aggressiveness, in both solid $[135,136]$ and hematological malignancies $[137,138]$.

\subsection{Collagen-binding integrins}

The $\alpha 1$ and $\alpha 2$ integrin chains have also been delineated in dermal myofibroblasts, but there is limited data on their CAF activity $[139,140]$. These chains are generally dispersed and may also be found in cancer cells, immune cells and vascular tissue [141-143]. In collagen gels, it has been shown that $\alpha 11$-mediated features that synergize through TGF $\beta$ depend on JNK signals [144]. Studies have shown a significant function for $\alpha 11$ in the endogenous stroma in cancer metastasis and development [145]. As $\alpha 11 \beta 1$ is limited to mesenchymally shaped fibroblasts, $\alpha 11$ may be a component of a gene pattern causing, the incursion of metastasizing neurons of breast cancer [146]. Moreover, it was illustrated that the siRNA knockdown of $\alpha 11$ decreases the invasion of cancer cells, as seen in Figure 5.

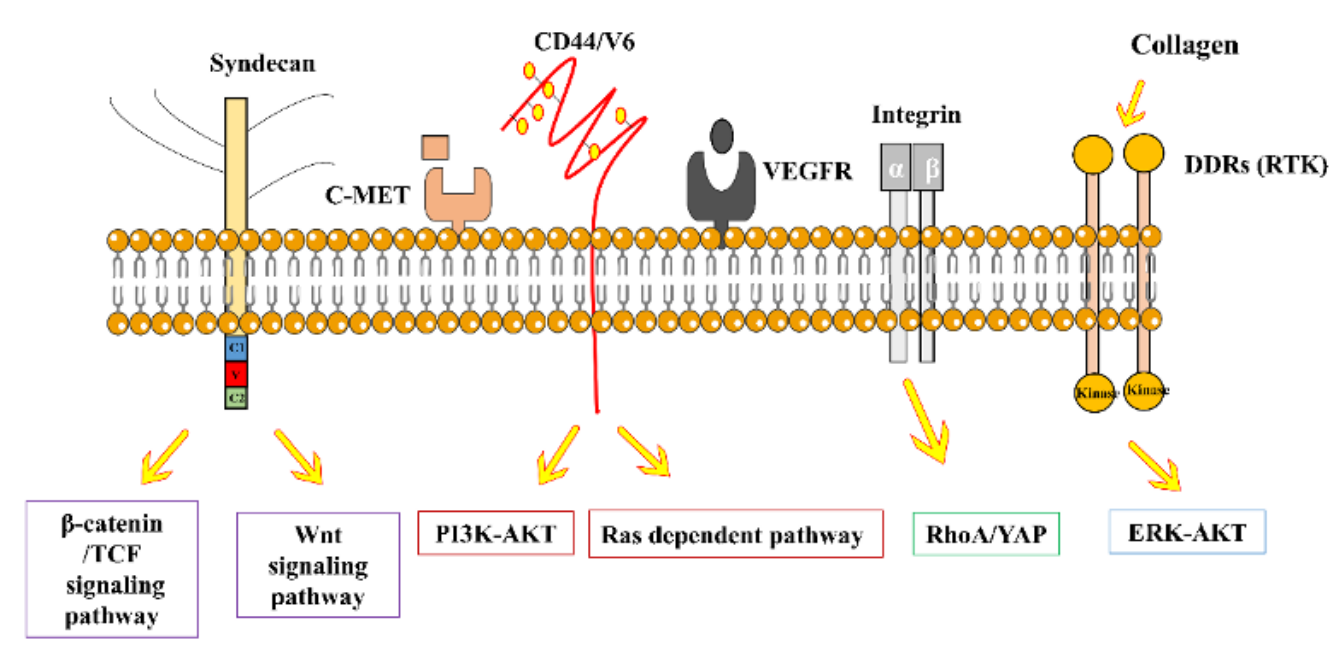

Effect on Proliferation, Metastases, Cell differentiation, and Migration

Figure 5. Extracellular matrix [ECM] and cancer signaling 


\subsection{EDA+ fibronectin-binding integrins}

Extra domain A-containing (EDA+) fibronectin, functions as a biomarker of activated fibroblasts in cancer stroma, scar regeneration and fibrosis $[147,148]$. Many receptors have been suggested for the addition of EDA+ fibronectin in fibroblasts, such as $\alpha 4 \beta 1$ and $\alpha 9 \beta 1$, which bind at a cryptic site [149]. TGF $\beta$ triggered myofibroblast differentiation was shown to require EDA+ Fibronectin [150].

\subsection{Integrin function and CAF differentiation}

Regardless of the stroma role, fibroblasts are most frequently activated in tumor stroma. Fibroblasts are differentiated into myofibroblasts characterized by $\alpha$-SMA and EDA+ fibronectin expression $[133,147]$. Two processes for the differentiation of progenitors into myofibroblasts are of major importance: cell contraction followed by a reorganization of the ECM and TGF $\beta$ signaling [151].

\subsection{CAF integrins and tumor cell proliferation}

Two other main loops maintain the activated state of CAFs, other paracrine processes influencing tumor cells or stem angiogenesis. For instance, tumor-secreted bidirectional PDGF-CC, which attracts PDGF $\alpha$ R-positive fibroblasts, thus influencing the production of FGF-7 and FGF-2 by CAFs, which plays a role in cell angiogenesis [152].

\subsection{CAF integrins and tumor stiffness}

The role of matrix stiffness may possibly be to modulate the activation of TGF $\beta$ on CAFs. It is probable that the latter has a fundamental role in the activation of the former in the tumor stroma. Accumulating evidence has demonstrated how a stiff matrix sensitizes the TGF $\beta$-LAP complex for activation $[153,154]$.

\subsection{Integrin function in CAF-promoted metastasis and invasion}

In vivo research has indicated that integrins on contractile CAFs are an incorporated component of matrix tunneling, thereby clearing the path for tumor cells to be invaded $[155,156]$. This method is accompanied by tissue, tumor and stage-specific induction of various MMPs $[155,157,158]$.

\subsection{Discoidin domain receptors}

Discoidin domain receptors (DDRs) are the tyrosine kinases receptors [RTKs] that their function is to bind to various collagens and MMP $[159,160]$. In this RTK class, there are two strongly associated receptors: DDR1 and DDR2 [161]. The DDRs also regulate basic procedures at the cellular stage, such as cell differentiation, proliferation, migration, and survival, typically controlled through RTKs. They also lead to the remodeling of ECM by regulating cell metalloproteinases' expression and function $[160,162,163]$.

\subsubsection{DDRs and cancer}

Several malignancies are defined by dysregulation or activity of one or more RTKs, which their dysregulated activity could promote the development of cancer. Thus, it is not unusual that cancer has changed the activity of DDRs. Dysregulated DDR signaling is believed to lead to a broad spectrum of cancers being malignant, including solid tumors and blood cancers, such as the brain, head, and neck, lung, prostate, breast, ovarian, head and neck, kidney, pancreatic cancer, lymphoma and leukemia [162]. As several separate functions have emerged, the role that is played by DDRs in malignancy is probably multifaceted. For example, DDR1 can regulate tissue migration, metastasis, and chemoresistance $[162,164,165]$. Correspondingly, DDR2 is essential for the promotion of metastasis [166] and may be an oncogenic trigger in pulmonary disease [167].

\subsection{Cell surface proteoglycans}

Studies have indicated that proteoglycans comprise a core protein that is covalently connected to one or more glycosaminoglycan chains. Only a small number of types of glycosaminoglycans have been identified in mammals, such as keratan sulfate (KS), hyaluronan (HA), heparan sulfate (HS) and chondroitin sulfate (CS) with closely-related dermatan phosphate (DS) [168]. HA is not sulfated 
or connected to a core protein and can be cross-linked with ECM proteins [157]. It is recognized as an important ECM component for tumor biology [169], as indicated in Fig5.

\subsubsection{The classes of cell surface proteoglycans}

There are two main types of cell surface proteoglycan, namely, syndecans and glypicans, both of which have a history of evolution. Syndecans are connected via a phospholipid anchor $[170,171]$ to the cell membrane and also, ECM macromolecules with heparin-binding characteristics have been discovered in all types of matrices. In wound repair processes, glycoproteins, like fibrinogen and fibronectin, the Von Willebrand factor, is critical and may be obtained from the circulation [172]. Others, including thrombospondins, tenascins, and CTGF/Cyr61/NOV (CCN) genes, such as matricellular proteins, are also produced in disease or response to tissue harm, such as tumors $[173,174]$. The processes require engagement and integration of RTKs with continuous ERK1,2 signaling [175]. This motif is prevalent in other proteoglycans on the cell surface, such as CD44 and syndecans. The enhanced manifestation of CSPG4 (with upregulated collagen VI) in individuals with soft tissue sarcoma is considered a prognostic factor [176].

\subsubsection{CD44-specific signaling}

CD44 has drawn much attention in tumor biology because tumor progression is strongly linked with the manifestation of some splice variants[32]. The version CD44v6 may function as a co-receptor by a receptor of the c-Met or vascular endothelial growth factor, where the ligand of the hepatocyte growth factor binds to both receptors [177]. In these examples, downstream signaling is complicated, incorporating Ras-dependent signals for preservation and opposition to apoptosis and Rac-1, which could enhance invasion and migration as well as actin cytoskeletal organization [178]. In reaction to the ECM relationships [179], the CD44v6 isoform can also detect the PI3K/AKT mechanism. CD44 is also of great importance as a cancer stem cell indicator in breast, prostate, pancreatic and colon cancer [180].

\subsubsection{Syndecans and cancer}

Even though there is little evidence that syndecans mutations play a key role in tumor progression, several trials have revealed changes in syndecan activity in solid and blood cancers [181,182]. However, it is uncertain whether expressed syndecans have a critical role in tumor progression participants or are bystanders. Moreover, syndecan- 1 activation has been correlated to tumor development and malignancy in myeloma [183,184]. In research regarding a mammalian carcinogenesis model of the mouse, it was elucidated that syndecan-1 is necessary for Wnt1 to promote tumor formation [185], which seems to be associated with $\beta$-catenin/TCF signaling [185].

\section{Angiogenesis}

Like all tissues, tumor cells require a blood flow. By creating fresh blood vessels [angiogenesis] through the growth and incorporation of endothelial cells, they acquire co-opting procedures that frequently operate in wound healing. Signals for angiogenesis include angiopoietin, interleukin (IL) 8, FGF, VEGF, and PDGF. PI3K-AKT signaling pathway regulates angiogenesis induction and stabilization of the vessel [119], with potential multifaced therapeutic windows in a broad spectrum of malignancies [186,187]. In addition, HIF1 stimulates the synthesis and secretion of VEGF in cancer cells. PI3K-AKT signaling increases HIF1 intensity and hyperactivation is also a significant element of angiogenesis. The HIF1 function is regulated by the Von Hippel-Lindau (VHL) core, an E3 ligase element that stimulates its ubiquitin-dependent degradation under normoxic conditions. VHL acts as a cancer suppressor and a diversity of tumors is involved in inactivating its genes. The PI3K-AKT pathway also regulates other angiogenic factors, like angiopoietins and nitric acid. The structure of unusual blood vessels has been shown to cause constitutive endothelial stimulation of AKT1. VEGF is sequestered in the ECM after its secretion and cannot exert its impact on endothelial cells until released by MMP9. These are secreted by macrophages and monocytes in the microenvironment of 
the tumor, thus highlighting the significance of immune cells in angiogenesis and the presence of a broader signaling network involving cancer cells. For angiogenesis to occur, thrombospondin 1 (Tsp1) is another variable that must be inhibited [188]. Angiogenesis is also orchestrated by bone marrow derived cellular population. In the last years, bone marrow niche emerged as a major determinant of tumor angiogenesis, representing a major source of several cytotypes [189-191]. Macrophages, neutrophils, mast cells, myeloid-lineage derived precursors actively participate in cancer-related inflammation, by providing a nursing environment orchestrated by the innate immunity, resulting in dynamic interaction with the angiogenic process within the tumor microenvironment. Additionally, several cell types cooperate in preventing the antiangiogenic drug activity on the endothelium [192]. Furthermore, a plethora of bone marrow-derived progenitors migrate within the cancer milieu actively participating in the neovascular wall, assuming endothelial or perycitic differentiation and functions [193-195], and modulating immune response[196,197].

\section{Inflammation}

Inflammatory cells can secrete FGF and EGF, which are essential to PI3K-AKT and Ras-ERK signaling regulators in cancer cells. They also generate colony-stimulating factor 1 (CSF1), a key signal that induces macrophages to secrete more EGF. VEGF and MMPs are also produced by immune cells that stimulate angiogenesis [198]. Furthermore, in both tumor-associated inflammatory cells and cancer cells, signaling via the transcription factor NF- $\mathrm{BB}$ [199] is essential, because it can support cell proliferation and growth, thus promoting cytokine production, like TNF. In some lymphoid malignancies, oncogenic diseases influence NF- $\kappa B$ or downstream effecters, like MALT1 and Bcl10. Moreover, in most tumors, cytokine activation usually increases NF- $\mathrm{BB}$ production. For instance, macrophage-produced TNF in colon cancer increases NF- $\kappa B$ production in intestinal epithelial cells, thereby promoting tumor preservation. Meanwhile, other cytokines, including IL-6 and IL-11, enhance concentrations of phospho-STAT3 [59], thus promoting cell proliferation. A similar process occurs in HCC and prostate cancer [200]. Activation of NF-kB also contributes to more TNF and prostaglandin E2 synthesis, which then promotes cell proliferation and cell polarity.

\section{Conclusion}

There seems to be no doubt that the knowledge and experience of cell signaling in cancers have significantly improved over the last 20 years. Furthermore, the cross-talk is known about in terms of how it could influence the treatment options and therapeutic combinations and contribute to drug resistance in the near future. Much more awareness of intracellular signaling networks and also cross-discussion among pathways and extracellular is needed if this approach is to continue to thrive in the coming decades.

Author Contributions: Conceptualization, B.B., A.D. and N.S.; methodology B.B., A.D. and N.S. ; resources, A.D. Z.R., S.T., H.S, R.V.A, N.T., A.A., B.B.; writing - review and editing, B.B., Z.R., A.D.; supervision, A.D. and N.S.

All authors have read and agreed to the published version of the manuscript.

Funding: This research received no external funding

Conflicts of Interest: The authors declare no conflict of interest 


\section{References}

1. Sanchez-Vega, F.; Mina, M.; Armenia, J.; Chatila, W.K.; Luna, A.; La, K.C.; Dimitriadoy, S.; Liu, D.L.; Kantheti, H.S.; Saghafinia, S.; et al. Oncogenic Signaling Pathways in The Cancer Genome Atlas. Cell 2018, 173, 321-337.e10.

2. Turner, N.; Grose, R. Fibroblast growth factor signalling: from development to cancer. Nat. Rev. Cancer 2010, 10, 116-129.

3. Hanahan, D.; Weinberg, R.A. The hallmarks of cancer. Cell 2000, 100, 57-70.

4. Solimini, N.L.; Luo, J.; Elledge, S.J. Non-oncogene addiction and the stress phenotype of cancer cells. Cell 2007, 130, 986-988.

5. Weinberg, R.A. The biology of cancer; Second edition.; Garland Science, Taylor \& Francis Group: New York, 2014; ISBN 978-0-8153-4219-9.

6. Garraway, L.A.; Lander, E.S. Lessons from the Cancer Genome. Cell 2013, 153, 17-37.

7. Vogelstein, B.; Papadopoulos, N.; Velculescu, V.E.; Zhou, S.; Diaz, L.A.; Kinzler, K.W. Cancer Genome Landscapes. Science 2013, 339, 1546-1558.

8. Komiya, Y.; Habas, R. Wnt signal transduction pathways. Organogenesis 2008, 4, 68-75.

9. Sever, R.; Glass, C.K. Signaling by Nuclear Receptors. Cold Spring Harb. Perspect. Biol. 2013, 5, a016709-a016709.

10. Futreal, P.A.; Coin, L.; Marshall, M.; Down, T.; Hubbard, T.; Wooster, R.; Rahman, N.; Stratton, M.R. A census of human cancer genes. Nat. Rev. Cancer 2004, 4, 177-183.

11. Hanahan, D.; Weinberg, R.A. Hallmarks of cancer: the next generation. Cell 2011, 144, 646-674.

12. Hallaj-Nezhadi, S.; Valizadeh, H.; Dastmalchi, S.; Baradaran, B.; Jalali, M.B.; Dobakhti, F.; Lotfipour, F. Preparation of chitosan-plasmid DNA nanoparticles encoding interleukin-12 and their expression in CT-26 colon carcinoma cells. J. Pharm. Pharm. Sci. Publ. Can. Soc. Pharm. Sci. Soc. Can. Sci. Pharm. 2011, 14, 181-195.

13. Vogelstein, B.; Kinzler, K.W. Cancer genes and the pathways they control. Nat. Med. 2004, 10, 789-799.

14. Skoda, A.M.; Simovic, D.; Karin, V.; Kardum, V.; Vranic, S.; Serman, L. The role of the Hedgehog signaling pathway in cancer: A comprehensive review. Bosn. J. Basic Med. Sci. 2018, 18, 8-20.

15. Kim, J.Y.; Park, G.; Krishnan, M.; Ha, E.; Chun, K.-S. Selective Wnt/ß-catenin Small-molecule Inhibitor CWP232228 Impairs Tumor Growth of Colon Cancer. Anticancer Res. 2019, 39, 3661-3667.

16. Nusse, R.; Clevers, H. Wnt/ $\beta$-Catenin Signaling, Disease, and Emerging Therapeutic Modalities. Cell 2017, 169, 985-999.

17. Hirate, Y.; Sasaki, H. The role of angiomotin phosphorylation in the Hippo pathway during preimplantation mouse development. Tissue Barriers 2014, 2, e28127.

18. Krishnamurthy, N.; Kurzrock, R. Targeting the Wnt/beta-catenin pathway in cancer: Update on effectors and inhibitors. Cancer Treat. Rev. 2018, 62, 50-60.

19. Jung, Y.-S.; Park, J.-I. Wnt signaling in cancer: therapeutic targeting of Wnt signaling beyond $\beta$-catenin and the destruction complex. Exp. Mol. Med. 2020.

20. Kim, M.; Jho, E.-H. Cross-talk between Wnt/ $\beta$-catenin and Hippo signaling pathways: a brief review. BMB Rep. 2014, 47, 540-545.

21. Luke, J.J.; Bao, R.; Sweis, R.F.; Spranger, S.; Gajewski, T.F. WNT/ $\beta$-catenin Pathway Activation Correlates with Immune Exclusion across Human Cancers. Clin. Cancer Res. Off. J. Am. Assoc. Cancer Res. 2019, 25, 3074-3083.

22. Argentiero, A.; De Summa, S.; Di Fonte, R.; Iacobazzi, R.M.; Porcelli, L.; Da Vià, M.; Brunetti, O.; Azzariti, A.; Silvestris, N.; Solimando, A.G. Gene Expression Comparison between the Lymph Node-Positive and 
-Negative Reveals a Peculiar Immune Microenvironment Signature and a Theranostic Role for WNT Targeting in Pancreatic Ductal Adenocarcinoma: A Pilot Study. Cancers 2019, 11.

23. Galluzzi, L.; Spranger, S.; Fuchs, E.; López-Soto, A. WNT Signaling in Cancer Immunosurveillance. Trends Cell Biol. 2019, 29, 44-65.

24. Mansoori, B.; Mohammadi, A.; Shirjang, S.; Baradaran, B. HMGI-C suppressing induces P53/caspase9 axis to regulate apoptosis in breast adenocarcinoma cells. Cell Cycle Georget. Tex 2016, 15, 2585-2592.

25. Moon, S.-H.; Huang, C.-H.; Houlihan, S.L.; Regunath, K.; Freed-Pastor, W.A.; Morris, J.P.; Tschaharganeh, D.F.; Kastenhuber, E.R.; Barsotti, A.M.; Culp-Hill, R.; et al. p53 Represses the Mevalonate Pathway to Mediate Tumor Suppression. Cell 2019, 176, 564-580.e19.

26. Gorgoulis, V.G.; Halazonetis, T.D. Oncogene-induced senescence: the bright and dark side of the response. Curr. Opin. Cell Biol. 2010, 22, 816-827.

27. Vargas, J.; Feltes, B.C.; Poloni, J. de F.; Lenz, G.; Bonatto, D. Senescence; an endogenous anticancer mechanism. Front. Biosci. Landmark Ed. 2012, 17, 2616-2643.

28. Bansal, R.; Nikiforov, M.A. Pathways of oncogene-induced senescence in human melanocytic cells. Cell Cycle Georget. Tex 2010, 9, 2782-2788.

29. Jones, S.; Zhang, X.; Parsons, D.W.; Lin, J.C.-H.; Leary, R.J.; Angenendt, P.; Mankoo, P.; Carter, H.; Kamiyama, H.; Jimeno, A.; et al. Core signaling pathways in human pancreatic cancers revealed by global genomic analyses. Science 2008, 321, 1801-1806.

30. Parsons, D.W.; Jones, S.; Zhang, X.; Lin, J.C.-H.; Leary, R.J.; Angenendt, P.; Mankoo, P.; Carter, H.; Siu, I.-M.; Gallia, G.L.; et al. An integrated genomic analysis of human glioblastoma multiforme. Science 2008, 321, $1807-1812$.

31. Wood, L.D.; Parsons, D.W.; Jones, S.; Lin, J.; Sjöblom, T.; Leary, R.J.; Shen, D.; Boca, S.M.; Barber, T.; Ptak, J.; et al. The genomic landscapes of human breast and colorectal cancers. Science 2007, 318, 1108-1113.

32. Günthert, U.; Hofmann, M.; Rudy, W.; Reber, S.; Zöller, M.; Haussmann, I.; Matzku, S.; Wenzel, A.; Ponta, H.; Herrlich, P. A new variant of glycoprotein CD44 confers metastatic potential to rat carcinoma cells. Cell 1991, $65,13-24$.

33. Santini, D.; Spoto, C.; Loupakis, F.; Vincenzi, B.; Silvestris, N.; Cremolini, C.; Canestrari, E.; Graziano, F.; Galluccio, N.; Salvatore, L.; et al. High concordance of BRAF status between primary colorectal tumours and related metastatic sites: implications for clinical practice. Ann. Oncol. Off. J. Eur. Soc. Med. Oncol. 2010, $21,1565$.

34. Gotwals, P.; Cameron, S.; Cipolletta, D.; Cremasco, V.; Crystal, A.; Hewes, B.; Mueller, B.; Quaratino, S.; Sabatos-Peyton, C.; Petruzzelli, L.; et al. Prospects for combining targeted and conventional cancer therapy with immunotherapy. Nat. Rev. Cancer 2017, 17, 286-301.

35. Gnoni, A.; Licchetta, A.; Memeo, R.; Argentiero, A.; Solimando, A.G.; Longo, V.; Delcuratolo, S.; Brunetti, O. Role of BRAF in Hepatocellular Carcinoma: A Rationale for Future Targeted Cancer Therapies. Medicina (Mex.) 2019, 55, 754.

36. Oddo, D.; Sennott, E.M.; Barault, L.; Valtorta, E.; Arena, S.; Cassingena, A.; Filiciotto, G.; Marzolla, G.; Elez, E.; van Geel, R.M.J.M.; et al. Molecular Landscape of Acquired Resistance to Targeted Therapy Combinations in BRAF-Mutant Colorectal Cancer. Cancer Res. 2016, 76, 4504-4515.

37. Da Vià, M.C.; Solimando, A.G.; Garitano-Trojaola, A.; Barrio, S.; Munawar, U.; Strifler, S.; Haertle, L.; Rhodes, N.; Teufel, E.; Vogt, C.; et al. CIC Mutation as a Molecular Mechanism of Acquired Resistance to Combined BRAF-MEK Inhibition in Extramedullary Multiple Myeloma with Central Nervous System Involvement. The Oncologist 2019.

38. Zhang, Y.; Kwok-Shing Ng, P.; Kucherlapati, M.; Chen, F.; Liu, Y.; Tsang, Y.H.; de Velasco, G.; Jeong, K.J.; 
Akbani, R.; Hadjipanayis, A.; et al. A Pan-Cancer Proteogenomic Atlas of PI3K/AKT/mTOR Pathway Alterations. Cancer Cell 2017, 31, 820-832.e3.

39. Schaub, F.X.; Dhankani, V.; Berger, A.C.; Trivedi, M.; Richardson, A.B.; Shaw, R.; Zhao, W.; Zhang, X.; Ventura, A.; Liu, Y.; et al. Pan-cancer Alterations of the MYC Oncogene and Its Proximal Network across the Cancer Genome Atlas. Cell Syst. 2018, 6, 282-300.e2.

40. Zou, J.; Li, P.; Lu, F.; Liu, N.; Dai, J.; Ye, J.; Qu, X.; Sun, X.; Ma, D.; Park, J.; et al. Notch1 is required for hypoxia-induced proliferation, invasion and chemoresistance of T-cell acute lymphoblastic leukemia cells. J. Hematol. Oncol.J Hematol Oncol 2013, 6, 3.

41. Aburjania, Z.; Jang, S.; Whitt, J.; Jaskula-Stzul, R.; Chen, H.; Rose, J.B. The Role of Notch3 in Cancer. The Oncologist 2018, 23, 900-911.

42. Alqudah, M.A.Y.; Agarwal, S.; Al-Keilani, M.S.; Sibenaller, Z.A.; Ryken, T.C.; Assem, M. NOTCH3 Is a Prognostic Factor That Promotes Glioma Cell Proliferation, Migration and Invasion via Activation of CCND1 and EGFR. PLoS ONE 2013, 8, e77299.

43. Yuan, X.; Wu, H.; Xu, H.; Han, N.; Chu, Q.; Yu, S.; Chen, Y.; Wu, K. Meta-analysis reveals the correlation of Notch signaling with non-small cell lung cancer progression and prognosis. Sci. Rep. 2015, 5, 10338.

44. Ramakrishnan, V.; Ansell, S.; Haug, J.; Grote, D.; Kimlinger, T.; Stenson, M.; Timm, M.; Wellik, L.; Halling, T.; Rajkumar, S.V.; et al. MRK003, a $\gamma$-secretase inhibitor exhibits promising in vitro pre-clinical activity in multiple myeloma and non-Hodgkin's lymphoma. Leukemia 2012, 26, 340-348.

45. Gonnissen, A.; Isebaert, S.; Haustermans, K. Targeting the Hedgehog signaling pathway in cancer: beyond Smoothened. Oncotarget 2015, 6, 13899-13913.

46. Jenkins, D. Hedgehog signalling: emerging evidence for non-canonical pathways. Cell. Signal. 2009, 21, 1023-1034.

47. Scales, S.J.; de Sauvage, F.J. Mechanisms of Hedgehog pathway activation in cancer and implications for therapy. Trends Pharmacol. Sci. 2009, 30, 303-312.

48. Richardson, C.J.; Schalm, S.S.; Blenis, J. PI3-kinase and TOR: PIKTORing cell growth. Semin. Cell Dev. Biol. 2004, 15, 147-159.

49. Diehl, J.A.; Zindy, F.; Sherr, C.J. Inhibition of cyclin D1 phosphorylation on threonine-286 prevents its rapid degradation via the ubiquitin-proteasome pathway. Genes Dev. 1997, 11, 957-972.

50. Sears, R.; Nuckolls, F.; Haura, E.; Taya, Y.; Tamai, K.; Nevins, J.R. Multiple Ras-dependent phosphorylation pathways regulate Myc protein stability. Genes Dev. 2000, 14, 2501-2514.

51. Rössig, L.; Jadidi, A.S.; Urbich, C.; Badorff, C.; Zeiher, A.M.; Dimmeler, S. Akt-dependent phosphorylation of p21(Cip1) regulates PCNA binding and proliferation of endothelial cells. Mol. Cell. Biol. 2001, 21, 5644-5657.

52. Burgering, B.M.T.; Medema, R.H. Decisions on life and death: FOXO Forkhead transcription factors are in command when PKB/Akt is off duty. J. Leukoc. Biol. 2003, 73, 689-701.

53. Ogawara, Y.; Kishishita, S.; Obata, T.; Isazawa, Y.; Suzuki, T.; Tanaka, K.; Masuyama, N.; Gotoh, Y. Akt enhances Mdm2-mediated ubiquitination and degradation of p53. J. Biol. Chem. 2002, 277, 21843-21850.

54. Xu, X.; Hou, Y.; Yin, X.; Bao, L.; Tang, A.; Song, L.; Li, F.; Tsang, S.; Wu, K.; Wu, H.; et al. Single-cell exome sequencing reveals single-nucleotide mutation characteristics of a kidney tumor. Cell 2012, 148, 886-895.

55. Ma, L.; Zhang, G.; Miao, X.-B.; Deng, X.-B.; Wu, Y.; Liu, Y.; Jin, Z.-R.; Li, X.-Q.; Liu, Q.-Z.; Sun, D.-X.; et al. Cancer stem-like cell properties are regulated by EGFR/AKT/ $\beta$-catenin signaling and preferentially inhibited by gefitinib in nasopharyngeal carcinoma. FEBS J. 2013, 280, 2027-2041.

56. Korkaya, H.; Paulson, A.; Charafe-Jauffret, E.; Ginestier, C.; Brown, M.; Dutcher, J.; Clouthier, S.G.; Wicha, M.S. Regulation of mammary stem/progenitor cells by PTEN/Akt/beta-catenin signaling. PLoS Biol. 2009, 7, 
e1000121.

57. Fuchs, E.; Horsley, V. More than one way to skin .. Genes Dev. 2008, 22, 976-985.

58. Fang, D.; Hawke, D.; Zheng, Y.; Xia, Y.; Meisenhelder, J.; Nika, H.; Mills, G.B.; Kobayashi, R.; Hunter, T.; Lu, Z. Phosphorylation of beta-catenin by AKT promotes beta-catenin transcriptional activity. J. Biol. Chem. 2007, 282, 11221-11229.

59. Harrison, D.A. The Jak/STAT pathway. Cold Spring Harb. Perspect. Biol. 2012, 4.

60. Thomas, C.; Gustafsson, J.-Å. The different roles of ER subtypes in cancer biology and therapy. Nat. Rev. Cancer 2011, 11, 597-608.

61. Li, S.; Shen, D.; Shao, J.; Crowder, R.; Liu, W.; Prat, A.; He, X.; Liu, S.; Hoog, J.; Lu, C.; et al. Endocrine-therapy-resistant ESR1 variants revealed by genomic characterization of breast-cancer-derived xenografts. Cell Rep. 2013, 4, 1116-1130.

62. Robinson, D.R.; Wu, Y.-M.; Vats, P.; Su, F.; Lonigro, R.J.; Cao, X.; Kalyana-Sundaram, S.; Wang, R.; Ning, Y.; Hodges, L.; et al. Activating ESR1 mutations in hormone-resistant metastatic breast cancer. Nat. Genet. 2013, 45, 1446-1451.

63. Toy, W.; Shen, Y.; Won, H.; Green, B.; Sakr, R.A.; Will, M.; Li, Z.; Gala, K.; Fanning, S.; King, T.A.; et al. ESR1 ligand-binding domain mutations in hormone-resistant breast cancer. Nat. Genet. 2013, 45, 1439-1445.

64. Castoria, G.; Lombardi, M.; Barone, M.V.; Bilancio, A.; Di Domenico, M.; De Falco, A.; Varricchio, L.; Bottero, D.; Nanayakkara, M.; Migliaccio, A.; et al. Rapid signalling pathway activation by androgens in epithelial and stromal cells. Steroids 2004, 69, 517-522.

65. Renoir, J.-M.; Marsaud, V.; Lazennec, G. Estrogen receptor signaling as a target for novel breast cancer therapeutics. Biochem. Pharmacol. 2013, 85, 449-465.

66. Harvey, K.F.; Hariharan, I.K. The Hippo Pathway. Cold Spring Harb. Perspect. Biol. 2012, 4, a011288-a011288.

67. Lin, J.I.; Poon, C.L.C.; Harvey, K.F. The Hippo size control pathway--ever expanding. Sci. Signal. 2013, 6, pe4.

68. Duronio, R.J.; Xiong, Y. Signaling pathways that control cell proliferation. Cold Spring Harb. Perspect. Biol. 2013, 5, a008904.

69. Capaccione, K.M.; Pine, S.R. The Notch signaling pathway as a mediator of tumor survival. Carcinogenesis 2013, 34, 1420-1430.

70. Zhang, X.; Tang, N.; Hadden, T.J.; Rishi, A.K. Akt, FoxO and regulation of apoptosis. Biochim. Biophys. Acta 2011, 1813, 1978-1986.

71. Shen, H.-M.; Tergaonkar, V. NFkappaB signaling in carcinogenesis and as a potential molecular target for cancer therapy. Apoptosis Int. J. Program. Cell Death 2009, 14, 348-363.

72. Ghoda, L.; Lin, X.; Greene, W.C. The 90-kDa Ribosomal S6 Kinase (pp90 rsk ) Phosphorylates the N-terminal Regulatory Domain of $\mathrm{I} \kappa \mathrm{B} \alpha$ and Stimulates Its Degradation in Vitro. J. Biol. Chem. 1997, 272, 21281-21288.

73. Kim, J.; Parrish, A.B.; Kurokawa, M.; Matsuura, K.; Freel, C.D.; Andersen, J.L.; Johnson, C.E.; Kornbluth, S. Rsk-mediated phosphorylation and 14-3-3e binding of Apaf-1 suppresses cytochrome c-induced apoptosis. EMBO J. 2012, 31, 1279-1292.

74. Kaelin, W.G.; McKnight, S.L. Influence of metabolism on epigenetics and disease. Cell 2013, 153, 56-69.

75. Plas, D.R.; Thompson, C.B. Akt-dependent transformation: there is more to growth than just surviving. Oncogene 2005, 24, 7435-7442.

76. Engelman, J.A.; Luo, J.; Cantley, L.C. The evolution of phosphatidylinositol 3-kinases as regulators of 
growth and metabolism. Nat. Rev. Genet. 2006, 7, 606-619.

77. Mîinea, C.P.; Sano, H.; Kane, S.; Sano, E.; Fukuda, M.; Peränen, J.; Lane, W.S.; Lienhard, G.E. AS160, the Akt substrate regulating GLUT4 translocation, has a functional Rab GTPase-activating protein domain. Biochem. J. 2005, 391, 87-93.

78. Barthel, A.; Okino, S.T.; Liao, J.; Nakatani, K.; Li, J.; Whitlock, J.P.; Roth, R.A. Regulation of GLUT1 gene transcription by the serine/threonine kinase Akt1. J. Biol. Chem. 1999, 274, 20281-20286.

79. Jensen, P.J.; Gunter, L.B.; Carayannopoulos, M.O. Akt2 modulates glucose availability and downstream apoptotic pathways during development. J. Biol. Chem. 2010, 285, 17673-17680.

80. Wieman, H.L.; Wofford, J.A.; Rathmell, J.C. Cytokine stimulation promotes glucose uptake via phosphatidylinositol-3 kinase/Akt regulation of Glut1 activity and trafficking. Mol. Biol. Cell 2007, 18, 1437-1446. 81. Ben-Sahra, I.; Howell, J.J.; Asara, J.M.; Manning, B.D. Stimulation of de novo pyrimidine synthesis by growth signaling through mTOR and S6K1. Science 2013, 339, 1323-1328.

82. Nakashima, A.; Kawanishi, I.; Eguchi, S.; Yu, E.H.; Eguchi, S.; Oshiro, N.; Yoshino, K.; Kikkawa, U.; Yonezawa, K. Association of CAD, a multifunctional protein involved in pyrimidine synthesis, with mLST8, a component of the mTOR complexes. J. Biomed. Sci. 2013, 20, 24.

83. Bakan, I.; Laplante, M. Connecting mTORC1 signaling to SREBP-1 activation. Curr. Opin. Lipidol. 2012, 23, 226-234.

84. Jeon, T.-I.; Osborne, T.F. SREBPs: metabolic integrators in physiology and metabolism. Trends Endocrinol. Metab. TEM 2012, 23, 65-72.

85. Guo, D.; Bell, E.H.; Mischel, P.; Chakravarti, A. Targeting SREBP-1-driven lipid metabolism to treat cancer. Curr. Pharm. Des. 2014, 20, 2619-2626.

86. Berwick, D.C.; Hers, I.; Heesom, K.J.; Moule, S.K.; Tavare, J.M. The identification of ATP-citrate lyase as a protein kinase B (Akt) substrate in primary adipocytes. J. Biol. Chem. 2002, 277, 33895-33900.

87. Edinger, A.L.; Thompson, C.B. Akt maintains cell size and survival by increasing mTOR-dependent nutrient uptake. Mol. Biol. Cell 2002, 13, 2276-2288.

88. Ying, H.; Kimmelman, A.C.; Lyssiotis, C.A.; Hua, S.; Chu, G.C.; Fletcher-Sananikone, E.; Locasale, J.W.; Son, J.; Zhang, H.; Coloff, J.L.; et al. Oncogenic Kras maintains pancreatic tumors through regulation of anabolic glucose metabolism. Cell 2012, 149, 656-670.

89. Miller, D.M.; Thomas, S.D.; Islam, A.; Muench, D.; Sedoris, K. c-Myc and cancer metabolism. Clin. Cancer Res. Off. J. Am. Assoc. Cancer Res. 2012, 18, 5546-5553.

90. Dang, C.V. MYC, metabolism, cell growth, and tumorigenesis. Cold Spring Harb. Perspect. Med. 2013, 3.

91. Vander Heiden, M.G.; Cantley, L.C.; Thompson, C.B. Understanding the Warburg effect: the metabolic requirements of cell proliferation. Science 2009, 324, 1029-1033.

92. Sever, R.; Brugge, J.S. Signal transduction in cancer. Cold Spring Harb. Perspect. Med. 2015, 5.

93. Luo, W.; Hu, H.; Chang, R.; Zhong, J.; Knabel, M.; O’Meally, R.; Cole, R.N.; Pandey, A.; Semenza, G.L. Pyruvate kinase M2 is a PHD3-stimulated coactivator for hypoxia-inducible factor 1. Cell 2011, 145, 732-744.

94. Gao, X.; Wang, H.; Yang, J.J.; Liu, X.; Liu, Z.-R. Pyruvate kinase M2 regulates gene transcription by acting as a protein kinase. Mol. Cell 2012, 45, 598-609.

95. Suzuki, S.; Tanaka, T.; Poyurovsky, M.V.; Nagano, H.; Mayama, T.; Ohkubo, S.; Lokshin, M.; Hosokawa, H.; Nakayama, T.; Suzuki, Y.; et al. Phosphate-activated glutaminase (GLS2), a p53-inducible regulator of glutamine metabolism and reactive oxygen species. Proc. Natl. Acad. Sci. U. S. A. 2010, 107, 7461-7466.

96. Kubatka, P.; Zihlavniková, K.; Kajo, K.; Péc, M.; Stollárová, N.; Bojková, B.; Kassayová, M.; Orendás, P. Antineoplastic effects of simvastatin in experimental breast cancer. Klin. Onkol. Cas. Ceske Slov. Onkol. Spolecnosti 
2011, 24, 41-45.

97. Vicente-Manzanares, M.; Horwitz, A.R. Cell migration: an overview. Methods Mol. Biol. Clifton NJ 2011, 769, $1-24$.

98. Devreotes, P.; Horwitz, A.R. Signaling networks that regulate cell migration. Cold Spring Harb. Perspect. Biol. 2015, 7, a005959.

99. Chin, Y.R.; Toker, A. Akt isoform-specific signaling in breast cancer: uncovering an anti-migratory role for palladin. Cell Adhes. Migr. 2011, 5, 211-214.

100. Birchmeier, W.; Birchmeier, C. Epithelial-mesenchymal transitions in development and tumor progression. In Epithelial-Mesenchymal Interactions in Cancer; Goldberg, I.D., Rosen, E.M., Eds.; Birkhäuser Basel: Basel, 1995; Vol. 74, pp. 1-15 ISBN 978-3-0348-9893-5.

101. Breunig, C.; Erdem, N.; Bott, A.; Greiwe, J.F.; Reinz, E.; Bernhardt, S.; Giacomelli, C.; Wachter, A.; Kanthelhardt, E.J.; Beißbarth, T.; et al. TGF $\beta 1$ regulates HGF-induced cell migration and hepatocyte growth factor receptor MET expression via C-ets-1 and miR-128-3p in basal-like breast cancer. Mol. Oncol. 2018, 12, 1447-1463.

102. Moschetta, M.; Basile, A.; Ferrucci, A.; Frassanito, M.A.; Rao, L.; Ria, R.; Solimando, A.G.; Giuliani, N.; Boccarelli, A.; Fumarola, F.; et al. Novel targeting of phospho-cMET overcomes drug resistance and induces antitumor activity in multiple myeloma. Clin. Cancer Res. Off. J. Am. Assoc. Cancer Res. 2013, 19, 4371-4382.

103. Paul, C.D.; Mistriotis, P.; Konstantopoulos, K. Cancer cell motility: lessons from migration in confined spaces. Nat. Rev. Cancer 2017, 17, 131-140.

104. Solimando, A.G.; Brandl, A.; Mattenheimer, K.; Graf, C.; Ritz, M.; Ruckdeschel, A.; Stühmer, T.; Mokhtari, Z.; Rudelius, M.; Dotterweich, J.; et al. JAM-A as a prognostic factor and new therapeutic target in multiple myeloma. Leukemia 2018, 32, 736-743.

105. Bendas, G.; Borsig, L. Cancer cell adhesion and metastasis: selectins, integrins, and the inhibitory potential of heparins. Int. J. Cell Biol. 2012, 2012, 676731.

106. Larue, L.; Bellacosa, A. Epithelial-mesenchymal transition in development and cancer: role of phosphatidylinositol 3' kinase/AKT pathways. Oncogene 2005, 24, 7443-7454.

107. Doble, B.W.; Woodgett, J.R. Role of glycogen synthase kinase-3 in cell fate and epithelial-mesenchymal transitions. Cells Tissues Organs 2007, 185, 73-84.

108. Hussey, G.S.; Chaudhury, A.; Dawson, A.E.; Lindner, D.J.; Knudsen, C.R.; Wilce, M.C.J.; Merrick, W.C.; Howe, P.H. Identification of an mRNP complex regulating tumorigenesis at the translational elongation step. Mol. Cell 2011, 41, 419-431.

109. Seibold, M.; Stühmer, T.; Kremer, N.; Mottok, A.; Scholz, C.-J.; Schlosser, A.; Leich, E.; Holzgrabe, U.; Brünnert, D.; Barrio, S.; et al. RAL GTPases mediate multiple myeloma cell survival and are activated independently of oncogenic RAS. Haematologica 2019, haematol.2019.223024.

110. Elsum, I.A.; Martin, C.; Humbert, P.O. Scribble regulates an EMT polarity pathway through modulation of MAPK-ERK signaling to mediate junction formation. J. Cell Sci. 2013, 126, 3990-3999.

111. Nagasaka, K.; Seiki, T.; Yamashita, A.; Massimi, P.; Subbaiah, V.K.; Thomas, M.; Kranjec, C.; Kawana, K.; Nakagawa, S.; Yano, T.; et al. A novel interaction between hScrib and PP1 $\gamma$ downregulates ERK signaling and suppresses oncogene-induced cell transformation. PloS One 2013, 8, e53752.

112. Dow, L.E.; Elsum, I.A.; King, C.L.; Kinross, K.M.; Richardson, H.E.; Humbert, P.O. Loss of human Scribble cooperates with H-Ras to promote cell invasion through deregulation of MAPK signalling. Oncogene 2008, 27, 5988-6001.

113. Shaikh, S.; Collier, D.A.; Sham, P.C.; Ball, D.; Aitchison, K.; Vallada, H.; Smith, I.; Gill, M.; Kerwin, R.W. 
Allelic association between a Ser-9-Gly polymorphism in the dopamine D3 receptor gene and schizophrenia. Hum. Genet. 1996, 97, 714-719.

114. Wu, M.; Pastor-Pareja, J.C.; Xu, T. Interaction between Ras(V12) and scribbled clones induces tumour growth and invasion. Nature 2010, 463, 545-548.

115. Iden, S.; van Riel, W.E.; Schäfer, R.; Song, J.-Y.; Hirose, T.; Ohno, S.; Collard, J.G. Tumor type-dependent function of the par3 polarity protein in skin tumorigenesis. Cancer Cell 2012, 22, 389-403.

116. McCaffrey, L.M.; Montalbano, J.; Mihai, C.; Macara, I.G. Loss of the Par3 polarity protein promotes breast tumorigenesis and metastasis. Cancer Cell 2012, 22, 601-614.

117. Xue, B.; Krishnamurthy, K.; Allred, D.C.; Muthuswamy, S.K. Loss of Par3 promotes breast cancer metastasis by compromising cell-cell cohesion. Nat. Cell Biol. 2013, 15, 189-200.

118. Siahmansouri, H.; Somi, M.H.; Babaloo, Z.; Baradaran, B.; Jadidi-Niaragh, F.; Atyabi, F.; Mohammadi, H.; Ahmadi, M.; Yousefi, M. Effects of HMGA2 siRNA and doxorubicin dual delivery by chitosan nanoparticles on cytotoxicity and gene expression of HT-29 colorectal cancer cell line. J. Pharm. Pharmacol. 2016, 68, 1119-1130.

119. Karar, J.; Maity, A. PI3K/AKT/mTOR Pathway in Angiogenesis. Front. Mol. Neurosci. 2011, 4, 51.

120. Nusse, R. Wnt signaling. Cold Spring Harb. Perspect. Biol. 2012, 4.

121. Kopan, R. Notch signaling. Cold Spring Harb. Perspect. Biol. 2012, 4.

122. Mazzone, M.; Selfors, L.M.; Albeck, J.; Overholtzer, M.; Sale, S.; Carroll, D.L.; Pandya, D.; Lu, Y.; Mills, G.B.; Aster, J.C.; et al. Dose-dependent induction of distinct phenotypic responses to Notch pathway activation in mammary epithelial cells. Proc. Natl. Acad. Sci. U. S. A. 2010, 107, 5012-5017.

123. Ingham, P.W. Hedgehog Signaling. Cold Spring Harb. Perspect. Biol. 2012, 4, a011221-a011221.

124. Thiery, J.P. Epithelial-mesenchymal transitions in tumour progression. Nat. Rev. Cancer 2002, 2, $442-454$.

125. Donnem, T.; Andersen, S.; Al-Shibli, K.; Al-Saad, S.; Busund, L.-T.; Bremnes, R.M. Prognostic impact of Notch ligands and receptors in nonsmall cell lung cancer: coexpression of Notch-1 and vascular endothelial growth factor-A predicts poor survival. Cancer 2010, 116, 5676-5685.

126. Keely, P.J. Mechanisms by which the extracellular matrix and integrin signaling act to regulate the switch between tumor suppression and tumor promotion. J. Mammary Gland Biol. Neoplasia 2011, 16, 205-219.

127. Bolós, V.; Gasent, J.M.; López-Tarruella, S.; Grande, E. The dual kinase complex FAK-Src as a promising therapeutic target in cancer. OncoTargets Ther. 2010, 3, 83-97.

128. Zhao, X.; Guan, J.-L. Focal adhesion kinase and its signaling pathways in cell migration and angiogenesis. Adv. Drug Deliv. Rev. 2011, 63, 610-615.

129. Rudelius, M.; Rosenfeldt, M.T.; Leich, E.; Rauert-Wunderlich, H.; Solimando, A.G.; Beilhack, A.; Ott, G.; Rosenwald, A. Inhibition of focal adhesion kinase overcomes resistance of mantle cell lymphoma to ibrutinib in the bone marrow microenvironment. Haematologica 2018, 103, 116-125.

130. Sun, C.-C.; Qu, X.-J.; Gao, Z.-H. Integrins: players in cancer progression and targets in cancer therapy. Anticancer. Drugs 2014, 25, 1107-1121.

131. Cantor, D.I.; Cheruku, H.R.; Nice, E.C.; Baker, M.S. Integrin $\alpha v \beta 6$ sets the stage for colorectal cancer metastasis. Cancer Metastasis Rev. 2015, 34, 715-734.

132. Liu, T.; Han, C.; Wang, S.; Fang, P.; Ma, Z.; Xu, L.; Yin, R. Cancer-associated fibroblasts: an emerging target of anti-cancer immunotherapy. J. Hematol. Oncol.J Hematol Oncol 2019, 12, 86.

133. Pietras, K.; Ostman, A. Hallmarks of cancer: interactions with the tumor stroma. Exp. Cell Res. 2010, 316, 1324-1331.

134. Eke, I.; Cordes, N. Focal adhesion signaling and therapy resistance in cancer. Semin. Cancer Biol. 2015, 31, $65-75$. 
135. Liu, T.; Zhou, L.; Li, D.; Andl, T.; Zhang, Y. Cancer-Associated Fibroblasts Build and Secure the Tumor Microenvironment. Front. Cell Dev. Biol. 2019, 7, 60.

136. Porcelli, L.; Iacobazzi, R.M.; Di Fonte, R.; Serratì, S.; Intini, A.; Solimando, A.G.; Brunetti, O.; Calabrese, A.; Leonetti, F.; Azzariti, A.; et al. CAFs and TGF- $\beta$ Signaling Activation by Mast Cells Contribute to Resistance to Gemcitabine/Nabpaclitaxel in Pancreatic Cancer. Cancers 2019, 11.

137. Raffaghello, L.; Vacca, A.; Pistoia, V.; Ribatti, D. Cancer associated fibroblasts in hematological malignancies. Oncotarget 2015, 6, 2589-2603.

138. Frassanito, M.A.; Desantis, V.; Di Marzo, L.; Craparotta, I.; Beltrame, L.; Marchini, S.; Annese, T.; Visino, F.; Arciuli, M.; Saltarella, I.; et al. Bone marrow fibroblasts overexpress miR-27b and miR-214 in step with multiple myeloma progression, dependent on tumour cell-derived exosomes. J. Pathol. 2019, 247, 241-253.

139. Arora, P.D.; Wang, Y.; Janmey, P.A.; Bresnick, A.; Yin, H.L.; McCulloch, C.A. Gelsolin and non-muscle myosin IIA interact to mediate calcium-regulated collagen phagocytosis. J. Biol. Chem. 2011, 286, 34184-34198.

140. Rodriguez, A.; Karen, J.; Gardner, H.; Gerdin, B.; Rubin, K.; Sundberg, C. Integrin alpha1beta1 is involved in the differentiation into myofibroblasts in adult reactive tissues in vivo. J. Cell. Mol. Med. 2009, 13, 3449-3462. 141. Wu, J.E.; Santoro, S.A. Complex patterns of expression suggest extensive roles for the $\alpha 2 \beta 1$ integrin in murine development. Dev. Dyn. 1994, 199, 292-314.

142. Pozzi, A.; Moberg, P.E.; Miles, L.A.; Wagner, S.; Soloway, P.; Gardner, H.A. Elevated matrix metalloprotease and angiostatin levels in integrin alpha 1 knockout mice cause reduced tumor vascularization. Proc. Natl. Acad. Sci. U. S. A. 2000, 97, 2202-2207.

143. Hemler, M.E.; Jacobson, J.G.; Strominger, J.L. Biochemical characterization of VLA-1 and VLA-2. Cell surface heterodimers on activated T cells. J. Biol. Chem. 1985, 260, 15246-15252.

144. Schulz, J.-N.; Zeltz, C.; Sørensen, I.W.; Barczyk, M.; Carracedo, S.; Hallinger, R.; Niehoff, A.; Eckes, B.; Gullberg, D. Reduced granulation tissue and wound strength in the absence of $\alpha 11 \beta 1$ integrin. J. Invest. Dermatol. 2015, 135, 1435-1444.

145. Navab, R.; Strumpf, D.; To, C.; Pasko, E.; Kim, K.S.; Park, C.J.; Hai, J.; Liu, J.; Jonkman, J.; Barczyk, M.; et al. Integrin $\alpha 11 \beta 1$ regulates cancer stromal stiffness and promotes tumorigenicity and metastasis in non-small cell lung cancer. Oncogene 2016, 35, 1899-1908.

146. Westcott, J.M.; Prechtl, A.M.; Maine, E.A.; Dang, T.T.; Esparza, M.A.; Sun, H.; Zhou, Y.; Xie, Y.; Pearson, G.W. An epigenetically distinct breast cancer cell subpopulation promotes collective invasion. J. Clin. Invest. 2015, 125, 1927-1943.

147. Kalluri, R.; Zeisberg, M. Fibroblasts in cancer. Nat. Rev. Cancer 2006, 6, 392-401.

148. Rybinski, B.; Franco-Barraza, J.; Cukierman, E. The wound healing, chronic fibrosis, and cancer progression triad. Physiol. Genomics 2014, 46, 223-244.

149. Shinde, A.V.; Bystroff, C.; Wang, C.; Vogelezang, M.G.; Vincent, P.A.; Hynes, R.O.; Van De Water, L. Identification of the peptide sequences within the EIIIA (EDA) segment of fibronectin that mediate integrin alpha9beta1-dependent cellular activities. J. Biol. Chem. 2008, 283, 2858-2870.

150. Serini, G.; Bochaton-Piallat, M.L.; Ropraz, P.; Geinoz, A.; Borsi, L.; Zardi, L.; Gabbiani, G. The fibronectin domain ED-A is crucial for myofibroblastic phenotype induction by transforming growth factor-beta1. J. Cell Biol. 1998, 142, 873-881.

151. Hinz, B. Formation and function of the myofibroblast during tissue repair. J. Invest. Dermatol. 2007, 127, 526-537.

152. Pietras, K.; Pahler, J.; Bergers, G.; Hanahan, D. Functions of paracrine PDGF signaling in the proangiogenic tumor stroma revealed by pharmacological targeting. PLoS Med. 2008, 5, e19. 
153. Klingberg, F.; Chow, M.L.; Koehler, A.; Boo, S.; Buscemi, L.; Quinn, T.M.; Costell, M.; Alman, B.A.; Genot, E.; Hinz, B. Prestress in the extracellular matrix sensitizes latent TGF- $\beta 1$ for activation. J. Cell Biol. 2014, 207, 283-297.

154. Baker, A.-M.; Bird, D.; Lang, G.; Cox, T.R.; Erler, J.T. Lysyl oxidase enzymatic function increases stiffness to drive colorectal cancer progression through FAK. Oncogene 2013, 32, 1863-1868.

155. Hooper, S.; Gaggioli, C.; Sahai, E. A chemical biology screen reveals a role for Rab21-mediated control of actomyosin contractility in fibroblast-driven cancer invasion. Br. J. Cancer 2010, 102, 392-402.

156. Gaggioli, C.; Hooper, S.; Hidalgo-Carcedo, C.; Grosse, R.; Marshall, J.F.; Harrington, K.; Sahai, E. Fibroblast-led collective invasion of carcinoma cells with differing roles for RhoGTPases in leading and following cells. Nat. Cell Biol. 2007, 9, 1392-1400.

157. Medjkane, S.; Perez-Sanchez, C.; Gaggioli, C.; Sahai, E.; Treisman, R. Myocardin-related transcription factors and SRF are required for cytoskeletal dynamics and experimental metastasis. Nat. Cell Biol. 2009, 11, 257-268.

158. Sanz-Moreno, V.; Gaggioli, C.; Yeo, M.; Albrengues, J.; Wallberg, F.; Viros, A.; Hooper, S.; Mitter, R.; Féral, C.C.; Cook, M.; et al. ROCK and JAK1 signaling cooperate to control actomyosin contractility in tumor cells and stroma. Cancer Cell 2011, 20, 229-245.

159. Fu, H.-L.; Valiathan, R.R.; Arkwright, R.; Sohail, A.; Mihai, C.; Kumarasiri, M.; Mahasenan, K.V.; Mobashery, S.; Huang, P.; Agarwal, G.; et al. Discoidin domain receptors: unique receptor tyrosine kinases in collagen-mediated signaling. J. Biol. Chem. 2013, 288, 7430-7437.

160. Leitinger, B. Discoidin domain receptor functions in physiological and pathological conditions. Int. Rev. Cell Mol. Biol. 2014, 310, 39-87.

161. Carafoli, F.; Mayer, M.C.; Shiraishi, K.; Pecheva, M.A.; Chan, L.Y.; Nan, R.; Leitinger, B.; Hohenester, E. Structure of the discoidin domain receptor 1 extracellular region bound to an inhibitory Fab fragment reveals features important for signaling. Struct. Lond. Engl. 1993 2012, 20, 688-697.

162. Valiathan, R.R.; Marco, M.; Leitinger, B.; Kleer, C.G.; Fridman, R. Discoidin domain receptor tyrosine kinases: new players in cancer progression. Cancer Metastasis Rev. 2012, 31, 295-321.

163. Borza, C.M.; Pozzi, A. Discoidin domain receptors in disease. Matrix Biol. J. Int. Soc. Matrix Biol. 2014, 34, 185-192.

164. Hidalgo-Carcedo, C.; Hooper, S.; Chaudhry, S.I.; Williamson, P.; Harrington, K.; Leitinger, B.; Sahai, E. Collective cell migration requires suppression of actomyosin at cell-cell contacts mediated by DDR1 and the cell polarity regulators Par3 and Par6. Nat. Cell Biol. 2011, 13, 49-58.

165. Jing, H.; Song, J.; Zheng, J. Discoidin domain receptor 1: New star in cancer-targeted therapy and its complex role in breast carcinoma. Oncol. Lett. 2018, 15, 3403-3408.

166. Zhang, K.; Corsa, C.A.; Ponik, S.M.; Prior, J.L.; Piwnica-Worms, D.; Eliceiri, K.W.; Keely, P.J.; Longmore, G.D. The collagen receptor discoidin domain receptor 2 stabilizes SNAIL1 to facilitate breast cancer metastasis. Nat. Cell Biol. 2013, 15, 677-687.

167. Hammerman, P.S.; Sos, M.L.; Ramos, A.H.; Xu, C.; Dutt, A.; Zhou, W.; Brace, L.E.; Woods, B.A.; Lin, W.; Zhang, J.; et al. Mutations in the DDR2 kinase gene identify a novel therapeutic target in squamous cell lung cancer. Cancer Discov. 2011, 1, 78-89.

168. Xu, D.; Esko, J.D. Demystifying heparan sulfate-protein interactions. Annu. Rev. Biochem. 2014, 83, $129-157$. 169. Milner, C.M.; Tongsoongnoen, W.; Rugg, M.S.; Day, A.J. The molecular basis of inter- $\alpha$-inhibitor heavy chain transfer on to hyaluronan. Biochem. Soc. Trans. 2007, 35, 672-676.

170. Nikitovic, D.; Tzardi, M.; Berdiaki, A.; Tsatsakis, A.; Tzanakakis, G.N. Cancer microenvironment and 
inflammation: role of hyaluronan. Front. Immunol. 2015, 6, 169.

171. Filmus, J.; Capurro, M.; Rast, J. Glypicans. Genome Biol. 2008, 9, 224.

172. Xian, X.; Gopal, S.; Couchman, J.R. Syndecans as receptors and organizers of the extracellular matrix. Cell Tissue Res. 2010, 339, 31-46.

173. Lowy, C.M.; Oskarsson, T. Tenascin C in metastasis: A view from the invasive front. Cell Adhes. Migr. 2015, 9, 112-124.

174. Gurbuz, I.; Chiquet-Ehrismann, R. CCN4/WISP1 (WNT1 inducible signaling pathway protein 1): a focus on its role in cancer. Int. J. Biochem. Cell Biol. 2015, 62, 142-146.

175. Price, M.A.; Colvin Wanshura, L.E.; Yang, J.; Carlson, J.; Xiang, B.; Li, G.; Ferrone, S.; Dudek, A.Z.; Turley, E.A.; McCarthy, J.B. CSPG4, a potential therapeutic target, facilitates malignant progression of melanoma. Pigment Cell Melanoma Res. 2011, 24, 1148-1157.

176. Cattaruzza, S.; Perris, R. Proteoglycan control of cell movement during wound healing and cancer spreading. Matrix Biol. J. Int. Soc. Matrix Biol. 2005, 24, 400-417.

177. Orian-Rousseau, V. CD44, a therapeutic target for metastasising tumours. Eur. J. Cancer Oxf. Engl. 1990 2010, 46, 1271-1277.

178. Bourguignon, L.Y.W.; Bikle, D. Selective Hyaluronan-CD44 Signaling Promotes miRNA-21 Expression and Interacts with Vitamin D Function during Cutaneous Squamous Cell Carcinomas Progression Following UV Irradiation. Front. Immunol. 2015, 6, 224.

179. Misra, S.; Hascall, V.C.; Markwald, R.R.; Ghatak, S. Interactions between Hyaluronan and Its Receptors (CD44, RHAMM) Regulate the Activities of Inflammation and Cancer. Front. Immunol. 2015, 6, 201.

180. Ajani, J.A.; Song, S.; Hochster, H.S.; Steinberg, I.B. Cancer stem cells: the promise and the potential. Semin. Oncol. 2015, 42 Suppl 1, S3-17.

181. Ramani, V.C.; Purushothaman, A.; Stewart, M.D.; Thompson, C.A.; Vlodavsky, I.; Au, J.L.-S.; Sanderson, R.D. The heparanase/syndecan-1 axis in cancer: mechanisms and therapies. FEBS J. 2013, 280, 2294-2306.

182. Yoneda, A.; Lendorf, M.E.; Couchman, J.R.; Multhaupt, H.A.B. Breast and ovarian cancers: a survey and possible roles for the cell surface heparan sulfate proteoglycans. J. Histochem. Cytochem. Off. J. Histochem. Soc. 2012, 60, 9-21.

183. Ramani, V.C.; Purushothaman, A.; Stewart, M.D.; Thompson, C.A.; Vlodavsky, I.; Au, J.L.-S.; Sanderson, R.D. The heparanase/syndecan-1 axis in cancer: mechanisms and therapies. FEBS J. 2013, 280, 2294-2306.

184. Solimando, A.G.; Da Vià, M.C.; Cicco, S.; Leone, P.; Di Lernia, G.; Giannico, D.; Desantis, V.; Frassanito, M.A.; Morizio, A.; Delgado Tascon, J.; et al. High-Risk Multiple Myeloma: Integrated Clinical and Omics Approach Dissects the Neoplastic Clone and the Tumor Microenvironment. J. Clin. Med. 2019, 8.

185. Alexander, C.M.; Reichsman, F.; Hinkes, M.T.; Lincecum, J.; Becker, K.A.; Cumberledge, S.; Bernfield, M. Syndecan-1 is required for Wnt-1-induced mammary tumorigenesis in mice. Nat. Genet. 2000, 25, 329-332.

186. Lamanuzzi, A.; Saltarella, I.; Desantis, V.; Frassanito, M.A.; Leone, P.; Racanelli, V.; Nico, B.; Ribatti, D.; Ditonno, P.; Prete, M.; et al. Inhibition of mTOR complex 2 restrains tumor angiogenesis in multiple myeloma. Oncotarget 2018, 9, 20563-20577.

187. Farhan, M.A.; Carmine-Simmen, K.; Lewis, J.D.; Moore, R.B.; Murray, A.G. Endothelial Cell mTOR Complex-2 Regulates Sprouting Angiogenesis. PLOS ONE 2015, 10, e0135245.

188. Green, D.R.; Llambi, F. Cell Death Signaling. Cold Spring Harb. Perspect. Biol. 2015, 7.

189. Qian, B.-Z.; Pollard, J.W. Macrophage diversity enhances tumor progression and metastasis. Cell 2010, 141, 39-51.

190. Zumsteg, A.; Christofori, G. Corrupt policemen: inflammatory cells promote tumor angiogenesis. Curr. 
Opin. Oncol. 2009, 21, 60-70.

191. Murdoch, C.; Muthana, M.; Coffelt, S.B.; Lewis, C.E. The role of myeloid cells in the promotion of tumour angiogenesis. Nat. Rev. Cancer 2008, 8, 618-631.

192. Ferrara, N. Pathways mediating VEGF-independent tumor angiogenesis. Cytokine Growth Factor Rev. 2010, 21, 21-26.

193. Patenaude, A.; Parker, J.; Karsan, A. Involvement of endothelial progenitor cells in tumor vascularization. Microvasc. Res. 2010, 79, 217-223.

194. Ziegelhoeffer, T.; Fernandez, B.; Kostin, S.; Heil, M.; Voswinckel, R.; Helisch, A.; Schaper, W. Bone marrow-derived cells do not incorporate into the adult growing vasculature. Circ. Res. 2004, 94, $230-238$.

195. Yoder, M.C.; Ingram, D.A. Endothelial progenitor cell: ongoing controversy for defining these cells and their role in neoangiogenesis in the murine system. Curr. Opin. Hematol. 2009, 16, 269-273.

196. Leone, P.; Di Lernia, G.; Solimando, A.G.; Cicco, S.; Saltarella, I.; Lamanuzzi, A.; Ria, R.; Frassanito, M.A.; Ponzoni, M.; Ditonno, P.; et al. Bone marrow endothelial cells sustain a tumor-specific CD8+ T cell subset with suppressive function in myeloma patients. Oncoimmunology 2019, 8, e1486949.

197. Albini, A.; Bruno, A.; Noonan, D.M.; Mortara, L. Contribution to Tumor Angiogenesis From Innate Immune Cells Within the Tumor Microenvironment: Implications for Immunotherapy. Front. Immunol. 2018, 9, 527.

198. Grivennikov, S.I.; Wang, K.; Mucida, D.; Stewart, C.A.; Schnabl, B.; Jauch, D.; Taniguchi, K.; Yu, G.-Y.; Osterreicher, C.H.; Hung, K.E.; et al. Adenoma-linked barrier defects and microbial products drive IL-23/IL-17-mediated tumour growth. Nature 2012, 491, 254-258.

199. Newton, K.; Dixit, V.M. Signaling in innate immunity and inflammation. Cold Spring Harb. Perspect. Biol. 2012, 4 .

200. Karin, M. NF-kappaB as a critical link between inflammation and cancer. Cold Spring Harb. Perspect. Biol. 2009, 1, a000141. 